\title{
Cryptic species and genetic connectivity among populations of the coral Pocillopora damicornis (Scleractinia) in the tropical southwestern Pacific
}

\author{
Oury Nicolas ${ }^{1,2,{ }^{*}}$, Gélin Pauline ${ }^{1}$, Magalon Hélène ${ }^{1,2}$
}

1 UMR ENTROPIE (Université de La Réunion, IRD, IFREMER, Université de Nouvehttps://w3.ifremer.fr/archimer-admin/author.jsp\#lle-Calédonie, CNRS), Université de La Réunion, St Denis, La Réunion, France

2 Laboratoire Cogitamus, Paris, France

*Corresponding author : Nicolas Oury, email address : nicolasoury@hotmail.fr

\begin{abstract}
:
Studying population genetic connectivity (i.e., identifying gene flow among populations and understanding their impacts on the genetic structure and diversity of populations) is first a matter of knowing what we work on, that is, accurately delimiting evolutionary units. Here, we focused on Pocillopora damicornis sensu stricto (or Pocillopora PSH04 sensu Gélin et al. in Mol Phylogenet Evol 109:430-446. http://dx.doi.org/10.1016/j.ympev.2017.01.018PANIST, 2017). From 458 colonies sampled within the tropical southwestern Pacific [Chesterfield Islands and New Caledonia (Grande Terre and Loyalty Islands)], Bayesian assignments and network analyses were conducted with 11-microsatellite loci to first evaluate the genetic partitioning of the colonies in distinct Secondary Species Hypotheses (SSHs), then in distinct clusters. Population genetic connectivity was then assessed for each cluster separately. Pocillopora PSH04 was partitioned into two highly differentiated SSHs (SSH04a and SSH04b), regularly found in sympatry. Furthermore, SSH04a was subdivided into two clusters (SSH04a-1 and SSH04a-2). This pattern of genetic structuring seems not related to clonality, but rather to the establishment of reproductive barriers. Nevertheless, considering each cluster separately, the populations appeared highly differentiated, suggesting relatively weak gene flow. This low connectivity among populations, coupled with the existence of cryptic species, brings new insights to the connectivity pattern of this understudied Pacific region.
\end{abstract}




\section{Introduction}

36 Population connectivity (i.e. the process linking habitats and populations geographically separated) is a powerful force that maintains the genetic cohesion of a species over its distribution range, via the homogenisation of genetic variations among its populations (Mayr 1963). In marine environments, population connectivity occurs through exchanges of individuals or propagules (e.g. gametes, eggs or larvae), synonym of a transfer of alleles (effective dispersal; Cowen et al. 2003; Cowen and Sponaugle 2009). Population genetic connectivity therefore represents a key element of population dynamics, genetic structuring and diversification processes of marine organisms (Palumbi 1992; Paulay and Meyer 2002; Cowen et al. 2003; Bowen et al. 2013). Thus, understanding genetic connectivity among populations appears mandatory to define effective management and conservation units (Mills and Allendorf 1996; Mönkkönen and Reunanen 1999; Drechsler et al. 2003).

Studying genetic connectivity among populations of scleractinian corals is particularly crucial in the context of declining coral reefs (Wilkinson 2008). Indeed, most of the physical structure and the primary production of coral reef ecosystems are supplied directly or indirectly by scleractinian corals (e.g. Hatcher 1990). Thus, better understanding the processes that govern coral ecosystems, and those that promote the resilience and recovery of coral populations, such as connectivity (Hughes et al. 2011), is fundamental. However, scleractinians adopt several reproduction strategies (reviewed in Harrison 2011), influencing the dispersive capabilities of the propagules, and so the connectivity. In particular, they can reproduce asexually through different processes [e.g. by fragmentation (Highsmith 1982) or production of asexual larvae (Stoddart 1983)], leading to the production of genetically identical colonies. In the presence of clonal or partially clonal populations, traditional estimators of genetic structure and connectivity among populations might be biased (Balloux et al. 2003; Halkett et al. 2005), as the Hardy-Weinberg equilibrium tends to be modified. This renders more complex genetic connectivity studies, but must be taken into account to faithfully assess the genetic structure of populations.

Nevertheless, studying population genetic connectivity is first a matter of knowing what we work on, that is, accurately delimiting the evolutionary units. Indeed, incorrectly delimiting species and misidentifying these units of connectivity lead to biased estimation of connectivity among populations, as belonging to distinct species or regrouping individuals from distinct sympatric species. This seems trivial, however with the recent development and democratisation of genetic tools, discoveries of highly divergent clusters among populations reveal the possible presence of cryptic species, that the sole use of traditional taxonomic (often morphological) characters may have not highlighted (reviewed in e.g. Knowlton 1993; Bickford et al. 2007; Fišer et al. 2018). As an illustration, within scleractinian corals, the morphospecies Stylophora pistillata, previously 
thought to be distributed in the whole Indo-Pacific and the Red Sea (Veron 2000), appears as a complex of species with narrower distribution range (Keshavmurthy et al. 2013), as the coral Porites lobata (Forsman et al. 2015). Two novel species of Leptastrea, formally considered as L. pruinosa, were also recently delimited and described in the Indo-Pacific (Arrigoni et al. 2020).

The widespread Indo-Pacific coral genus Pocillopora particularly illustrates this issue, as phenotypic plasticity encrypts the morphospecies boundaries and complicates the definition of valid taxonomic units (see Todd 2008). Thus, in the last decade, several molecular approaches have contributed to the investigation of Pocillopora species boundaries (summarized in Gélin et al. 2017a). For example, the morphospecies P. damicornis (Linnaeus 1758; referred as P. damicornis sensu lato hereafter to avoid any ambiguity) was disentangled in five genetic lineages:

$P$. damicornis types $\alpha, \beta, \delta, \gamma$ and $\varepsilon$ (Schmidt-Roach et al. 2012a), a posteriori defined as five distinct species and named P. damicornis (Linnaeus 1758), P. acuta (Lamarck 1816), P. aliciae (Schmidt-Roach, Miller and Andreakis 2013), P. verrucosa (Ellis and Solander 1786) and P. brevicornis (Lamarck 1816), respectively (Schmidt-Roach et al. 2014). Besides, using species delimitation methods based on genetic data, Gélin et al. (2017a) defined within the Pocillopora genus 16 Primary Species Hypotheses (PSHs sensu Pante et al. 2015), with some of them partitioned into several Secondary Species Hypotheses (SSHs sensu Pante et al. 2015), themselves partitioned into several divergent genetic clusters, often found in sympatry at the site scale. In this latter study, lineages $\alpha$ (PSH04 therein), $\delta$ (PSH03) and $\varepsilon$ (PSH10) appeared as unique entities with no further genetic partitioning into SSH, but this needs to be confirmed by completing the sampling and further genetic analyses. However lineage $\beta$ (PSH05) was found to be subdivided in different SSHs and clusters, revealing possible cryptic species in this lineage (Gélin et al. 2017a, b, 2018b), such as for lineage $\gamma$, whose ORF haplotypes were shared between PSH13 and PSH16 (Gélin et al. 2017a) and which therefore needs to have its limits refined (Oury et al. submitted).

Here, we focused on P. damicornis type $\alpha$ sensu Schmidt-Roach et al. (2012a) or PSH04 sensu Gélin et al. [2017a; also corresponding to Pocillopora type 4 sensu Pinzón et al. (2013) and Pocillopora Clade Ib sensu Marti-Puig et al. (2014); referred as P. damicornis sensu stricto hereafter to avoid confusing it with the morphospecies (i.e. P. damicornis s.l.)]. Pocillopora damicornis s.s. is common and found in lagoons and shallow waters from the East and West coasts of Australia (Pinzón et al. 2013; Torda et al. 2013a, b; Thomas et al. 2014; Schmidt-Roach et al. 2014), the northwestern subtropical and southwestern tropical regions of the Pacific Ocean (Pinzón et al. 2013; Gélin et al. 2017a). Colonies are also present, but rare, in the southwestern Indian Ocean (two colonies over thousands sampled; Gélin et al. 2017a) and in the central and northeastern Pacific (Pinzón et al. 2013). It is a broadcast spawner (Schmidt-Roach et al. 2012b), and is also able to propagate asexually (Torda et al. 2013a, b; Thomas et al. 2014) through fragmentation or release 
of asexually produced larvae (Schmidt-Roach et al. 2012a). Previous studies (Richmond 1987; Harii et al. 2002) reported a pelagic larval stage with zooxanthellae ranging from few hours to $\sim 100$ days, suggesting high dispersal abilities. However, this must be taken cautiously, as inferred from P. damicornis s.l. (probably P. acuta).

For now, few studies clearly investigated genetic connectivity in this redefined species as previous studies dealt with $P$. damicornis s.l. and it was not always possible to identify a posteriori the studied lineage(s). Besides, a relatively small part of its distribution range is covered. Thus, in the Great Barrier Reef (GBR) region, strong genetic similarities at large spatial scales (approximately 1,000 km) were observed among populations of $P$. damicornis s.s. However, populations relatively close geographically were more differentiated (Torda et al. 2013b). On the contrary, in western Australia (Ningaloo Reef and Muiron Islands), populations of P. damicornis s.s. geographically close were poorly differentiated, while the differentiation among populations increased with distance (Thomas et al. 2014). In both studies, clonality was important [13.7\% of the colonies shared their multi-locus genotype (MLG) with at least one other colony in Torda et al. (2013b); 84 different MLGs were identified among 162 colonies in Thomas et al. (2014)].

In front of such a lack of knowledge for P. damicornis s.s., and regarding the sampling locations were we found it, we inferred the genetic connectivity among populations from an ecoregion (sensu Spalding et al. 2007) located in the southern part of the distribution range of the genus, which is largely understudied: New Caledonia. This ecoregion includes several archipelagos comprising small islands (Chesterfield and Loyalty Islands) and one main island (Grande Terre). Some are inhabited (Grande Terre and Loyalty Islands), with growing disturbances on marine environment (e.g. coastal anthropisation, tourism, mining), while some others are uninhabited (Chesterfield Islands), and thus relatively poorly influenced by human activities. Besides, this area is protected by one of the largest Marine Protected Areas (MPAs): the Natural Park of the Coral Sea $\left(1.3 \times 10^{6} \mathrm{~km}^{2}\right)$. This ecoregion thus represents an interesting patched framework to study population connectivity in habitats differently impacted by human activities, but few studies focused on this particular area (e.g. Planes et al. 1998; Postaire et al. 2017; Gélin et al. 2018b), especially in models with a life history similar to Pocillopora.

In this study, we first explored the genetic partitioning within Pocillopora PSH04, using assignment and network analyses based on 11-microsatellite genotypes. Then, once all units of connectivity (i.e. the clusters) were defined, the genetic diversity and the connectivity among populations from New Caledonia ecoregion were assessed for each unit separately. 


\section{Material and methods}

140 Sampling design

141 Pocillopora colonies were collected between March 2001 and October 2016 within three marine

142 provinces (sensu Spalding et al. 2007): the western Indian Ocean, the tropical southwestern Pacific

143 and the southeastern Polynesia, representing six ecoregions (sensu Spalding et al. 2007), 16

144 localities (Fig. 1) and over hundred sampling sites. Different habitats (reef slope, fringing reef, flat

145 reef or lagoon) were sampled, at various depths (from sea surface to $30 \mathrm{~m}$ depth), to maximise

146 colonies genetic diversity. On each site, colonies were haphazardly sampled (branch tip +

147 photograph) by snorkelling or scuba diving, without any a priori on morphology (a non-

148 discriminant character in this genus; Pinzón et al. 2013; Schmidt-Roach et al. 2014; Gélin et al.

149 2017a), except in southeastern Polynesia, where the sampling focused on colonies presenting

$150 P$. verrucosa macromorphology (but which could be $P$. damicornis s.s.). Samples were fixed in

$15190 \%$ ethanol at lab and stored at room temperature.

152

153 DNA extraction, microsatellite genotyping and species identification

154 From the sampled colonies, DNA was extracted using DNeasy Blood \& Tissue kit (Qiagen ${ }^{\mathrm{TM}}$ ).

155 Samples were genotyped using 13 microsatellite loci, as in Gélin et al. (2017a; Online Resource 1).

156 Then, colonies belonging to Pocillopora PSH04 were identified a posteriori of sampling and $a$

157 priori of analyses using assignment tests performed with STRUCTURE 2.3.4 (Pritchard et al. 2000),

158 by compiling all the genotypes with the 975 ones from Gélin et al. (2017a), corresponding to

159 colonies from various PSHs already identified and whose ORF has been sequenced. Five iterations

160 of STRUCTURE were run at $K=12$ (this value was found to retrieve the main PSHs in Gélin et al.

161 2017a), with the same parameters as in Gélin et al. (2017a). Colonies assigned to the cluster

162 corresponding to Pocillopora PSH04 (ORF07-17) with a mean probability over the five runs of at

163 least 0.75 (i.e. the mean assignment probability to include all colonies with PSH04 ORF haplotypes

164 but none with other haplotypes) were retained and constitute the dataset for this study (Online

165 Resource 2). 


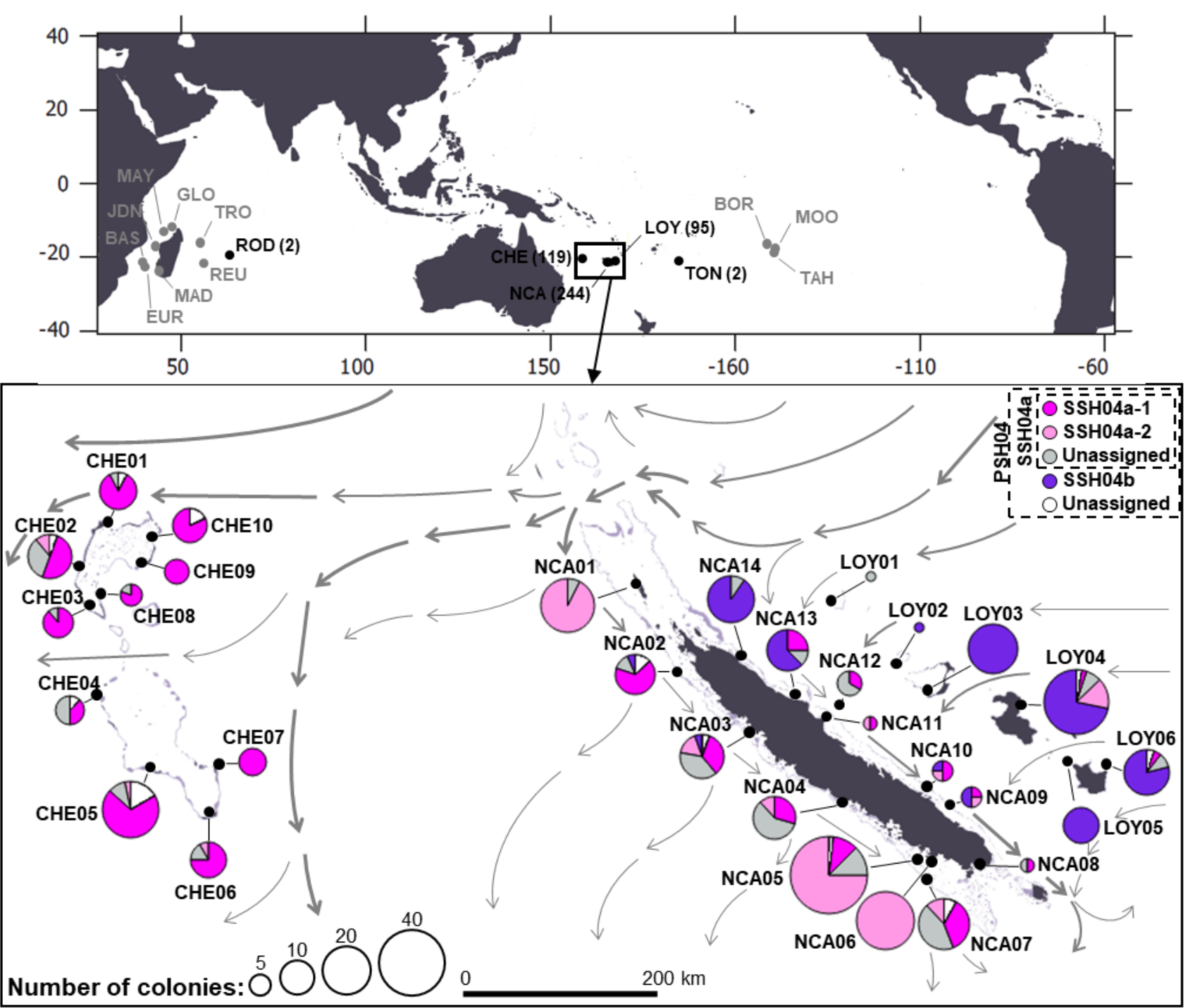

Fig. 1 Sampling localities of Pocillopora spp. colonies [from West to East and North to South: GLO: Glorioso Islands; MAY: Mayotte; JDN: Juan de Nova Island; BAS: Bassas da India; EUR: Europa Island; MAD: Madagascar; TRO: Tromelin Island; REU: Reunion Island; ROD: Rodrigues Island; CHE: Chesterfield Islands; NCA: New Caledonia (Grande Terre); LOY: Loyalty Islands; TON: Tonga; BOR: Bora-Bora; MOO: Moorea and TAH: Tahiti]. Localities for which colonies of Pocillopora PSH04 have been identified are in black (the number of colonies is indicated in parentheses). New Caledonia ecoregion is detailed below. Sites (detailed in Online Resource 4) are numerically identified from the locality code and the distribution of PSH04 clusters is represented [white and light grey represent the proportions of PSH04 colonies not assigned $(P<0.75)$ to a Secondary Species Hypothesis $(\mathrm{SSH})$ or to a SSH04a cluster, respectively]. Arrows indicate the main currents (width proportional to speed; Vega et al. 2006)

Global diversity and clonality

177 For each locus, the number of alleles $(\mathrm{Na})$ and the percentage of missing data $(\% \mathrm{NA})$ were estimated. Then, the occurrence of identical multi-locus genotypes (MLGs) among the colonies was assessed with GENCLONE 2.0 (Arnaud-Haond and Belkhir 2007). The probability of obtaining the same MLG twice or more from distinct random reproductive events was further estimated using $P_{\mathrm{SEX}}\left(F_{I S}\right)$ (Arnaud-Haond et al. 2007). However, as GENCLONE considers missing data as different alleles (Arnaud-Haond and Belkhir 2007), the number of different MLGs in a population ( $\left.N_{M L G}\right)$ could be overestimated. Thus, the genotypes of the colonies were also compared manually by considering missing data as potentially identical alleles. This latter method provides an 
underestimation of $N_{M L G}$, but combined with GENCLONE method, both methods provide a range containing the true value of $N_{M L G}$. The clonal richness $R$ (Dorken and Eckert 2001) was then calculated over all colonies and for each method, with the formula: $R=\frac{\left(N_{M L G}-1\right)}{(N-1)}$. Potential multilocus lineages (MLLs) were identified using GENOTYPE (Meirmans and van Tienderen 2004), considering missing data as potentially identical alleles. Pairwise genetic distances based on mutational steps under both the Infinite Allele Model (IAM) and the Stepwise Mutational Model (SMM) were calculated for all pairs of MLGs, and a threshold in the genetic distance distribution was determined, under which distinct MLGs were considered to belong to the same MLL.

\section{Genetic partitioning exploration}

All further analyses were performed on both the entire dataset (i.e. keeping all colonies) and a truncated one (i.e. keeping one representative per potential MLG per population, considering missing data as potentially identical alleles), as suggested in Alberto et al. (2005). Indeed, while repeated MLGs can bias estimators which are not designed for clonal populations, colonies with the same genotype participate equally to sexual reproduction and gene flow, and should not be ignored. Therefore, analysing both datasets should take into account the effect of clonality.

First, null alleles and other potential technical biases were assessed with MiCROCHECKER 2.2.3 (van Oosterhout et al. 2004), and genotypic linkage disequilibrium was tested with GENEPOP 4.7.0 (Raymond and Rousset 1995; Rousset 2008). Then, to infer the genetic partitioning within PSH04, we used and compared the results of assignment tests [STRUCTURE (Pritchard et al. 2000) and DAPC (Jombart et al. 2010)], Minimum Spanning Trees (MST; EDENETWORKS 2.18; Kivelä et al. 2015), allelic frequencies and $F_{S T}$ (Weir and Cockerham 1984), as in Gélin et al. (2018a; see the Supplementary Method in Online Resource 3 for more details). We then defined the most likely number of genetically homogeneous groups $(K)$ within the colonies as the highest $K$ for which all previous methods were congruent for each dataset (i.e. the entire and the truncated). This level of differentiation should correspond to the SSH level.

In a hierarchical approach, and as a first level of structuration can hide a second one (see Gélin et al. 2018a), these analyses were repeated on each SSH separately. Once this second level of structuration has been tested, we defined the final number of genetic homogeneous groups (i.e. the clusters). Afterwards, we considered a population as all the colonies assigned to a given cluster with a probability of at least 0.75 (i.e. the minimum probability for which assignments in all datasets are strictly identical), sampled on the same site, at the same date (usually during a single dive and at the same depth). Colonies not assigned to a cluster with a probability $\geq 0.75$ were considered admixed (i.e. assigned to more than one cluster due to hybridization, shared ancestry or bad assignment due to missing data). NEwHYBRIDS 1.1 (Anderson and Thompson 2002) was then run with $10^{6}$ 
iterations after a burn-in period of $10^{5}$, to detect whether the admixed colonies could be considered as hybrids.

\section{Genetic diversity and connectivity within each cluster}

Allelic diversity

For each locus and each population, $\% N A$, the percentage of missing data, $N a$, the number of alleles and $N p$, the number of population-private alleles, were estimated using FSTAT 2.9.3 (Goudet 2001). Then, for each population, mean indices (\%NA pop, $N a_{p o p}$ and $N p_{p o p}$, respectively) were calculated over all loci, as the percentage of polymorphic loci $(P)$. The clonal richness $R$ (Dorken and Eckert 2001) was also estimated for each population, as previously.

Afterwards, only the populations with $N \geq 10$ were considered. The observed heterozygosity

$231(\mathrm{Ho})$, the expected heterozygosity at Hardy-Weinberg equilibrium (He, gene diversity) and the inbreeding coefficient ( $F_{I S}$; Wright 1931) were calculated with FSTAT 2.9.3 (Goudet 2001), for each locus and each population, and then for all loci within each population (noted $\mathrm{Ho}_{\text {pop }}, \mathrm{He}_{\mathrm{pop}}$ and

Genetic connectivity

Two genetic differentiation indices were estimated among populations: $F_{S T}$ (Weir and Cockerham 1984) and $D_{\text {est }}$ (Jost 2008). $F_{S T}$ were estimated using GENEPOP 4.7.0 (Raymond and Rousset 1995; Rousset 2008), while $D_{\text {est }}$ with the package 'diveRsity' (Keenan et al. 2013) of the software R 3.3.1 (R Core Team 2016). Directional gene flow between populations were assessed by constructing a relative migration network with divMigrate (Sundqvist et al. 2016), implemented in the R package 'diveRsity' (Keenan et al. 2013). Finally, for each cluster, a population-based network was built using EDENETWORKS 2.18 (Kivelä et al. 2015) and the $F_{S T}$ distance (Weir and Cockerham 1984). Populations with $N<10$ were included. All networks were built at the same threshold [defined at the lowest percolation threshold (Dpe) found among clusters; i.e. the lowest $F_{S T}$ threshold, below which the network is fragmented; Rozenfeld et al. 2007] to allow their comparison.

\section{Sampling and Pocillopora species identification}

250 Over all localities, more than 9,000 colonies of Pocillopora were sampled, among which 462 251 colonies were assigned to PSH04 (Online Resource 2), all found in lagoons or upper reef slopes, 252 between sea surface and $5 \mathrm{~m}$ depth (Online Resource 4). Among these 462 colonies, two were sampled in Rodrigues Island, in the southwestern Indian Ocean, and 460 in the tropical southwestern Pacific, within two ecoregions (sensu Spalding et al. 2007): New Caledonia $(N=458$ 
colonies) and Tonga Islands ( $N=2$ colonies; Fig. 1$)$. The colonies from New Caledonia ecoregion constitute the final dataset of this study. They were sampled on 30 sites within three localities:

257 Chesterfield Islands (10 sites; CHE01-10; $N=119$ colonies), Grande Terre (14 sites; NCA01-14; $258 N=244$ colonies) and Loyalty Islands (6 sites; LOY01-06; $N=95$ colonies; Fig. 1; Online 259 Resource 4).

\section{Global diversity and clonality}

262 Among the 458 genotypes of the colonies retained, missing data represented $17.5 \%$. Two loci 263 (Poc40 and Pd3-009) showed very high levels of missing data (86.2\% and 33.4\%, respectively;

264 Online Resource 1), and were not considered for further analyses, reducing the global proportion of missing data to 9.8\%. An additional three loci (PV2, Pd3-005 and Pd3-EF65) showed relatively high levels of missing data $(15.3 \%<\% N A<19.7 \%)$ compared to the eight others $(3.2 \%<\% N A<8.6 \%$; Online Resource 1). To deal with the high levels of missing data for these three loci without losing any crucial information, we decided to perform the analyses at 8 and 11 loci $(\% N A=6.7 \%$ and 9.8\%, respectively; Table 1; Online Resource 1). All 11 loci were polymorphic, with a number of alleles per locus varying from 5 for Pd3-004 to 22 for Pd3-005 (Online Resource 1).

At 11 loci, 454 and 420 different MLGs over 458 colonies were detected, considering missing data as different or potentially identical alleles, respectively. Thus, the clonal richness $R$ of the dataset was comprised between 0.99 and 0.92, respectively (Table 1). Considering missing data as different alleles (GENCLONE method), over the 454 MLGs found, one MLG was repeated four times in NCA01, and a second twice in LOY03. For both MLGs, $P_{\mathrm{SEX}}\left(F_{I S}\right)$ was very low $\left(<10^{-12}\right)$, indicating that the colonies came from a single sexual reproduction event and belonged to the same genet. However, only two colonies actually shared the same MLG at 13 loci. Considering missing data as potentially identical alleles, at least 27 MLGs were shared by a minimum of two colonies, but only three were shared between two colonies sampled in different sites, distant from 200 to $280 \mathrm{~km}$. When reducing the number of loci to 8, 428 and 393 different MLGs over 458 colonies were detected considering missing data as different or potentially identical alleles, respectively $(0.86<R<0.93$; Table 1$)$. According to GENCLONE (missing data as different alleles), 16 MLGs were repeated in two to seven colonies from the same site, except for one MLG shared between colonies from NCA01 and NCA05, distant from more than $400 \mathrm{~km}$. However, $P_{\mathrm{SEX}}\left(F_{I S}\right)$ was comprised between $10^{-1}$ and $10^{-17}$, suggesting that some colonies sharing the same MLG are probably not ramets from the same genet. With the other method (i.e. missing data as potentially identical alleles), at least 37 MLGs were found more than once, sometimes among very distant 
colonies $(>750 \mathrm{~km})$. Thus, keeping one representative per MLG and per population resulted in truncated datasets of 423 and 395 colonies at 11 and 8 loci, respectively (Table 1).

Both at 11 and 8 loci, no clear truncature was observed in the distribution of the pairwise genetic distances between MLGs under the IAM and the SMM (Online Resource 5), making difficult to define the threshold distinguishing MLGs from the same MLL. We thus considered that MLGs belong to the same MLL when they differed from one allele (IAM) or two mutational steps (SMM), as in a previous study focusing on P. acuta (PSH05; Gélin et al. 2018b). Considering these thresholds, between 330 (IAM) and 389 (SMM) MLLs were detected at 11 loci, and between 161 (IAM) and 265 (SMM) at 8 loci.

Table 1 Summary of the different Pocillopora PSH04 datasets analysed. $N_{l o c i}, N$, and $N_{M L G}$ : numbers of loci, colonies and multi-locus genotypes (MLGs), respectively; \%NA: percentage of missing data; NA treatment: treatment of missing data (different of potentially identical alleles) for the identification of MLGs and $R$ : clonal richness (Dorken and Eckert 2001)

\section{Genetic partitioning exploration}

304 Further analyses were performed on the four datasets summarised in Table 1 (i.e. an entire and a 305 truncated one, both at 11 and 8 loci). No null allele nor other potential scoring error was detected with MiCRO-CHECKER. Moreover, no genotypic linkage disequilibrium was found. Thus, all loci (11 or 8 depending on the datasets) were kept.

All results were very similar for the four datasets (Online Resource 6), so we presented here the results for the most complete one (Entire_11), specifying when differences were observed. For $K=2$ and $K=3$, the five runs of STRUCTURE were similar and congruent with DAPC (Fig. 2;

311 Online Resources 7-9). From $K=4$, the results of the two methods became incongruent, with more 312 differences between datasets (Online Resources 6-7). The MST retrieved the genetic groups at $313 K=2$ (Online Resource 8c), but not at $K=3$ (Fig. 2c). Moreover, at $K=2$, the allelic frequencies of 314 each group were very different (Online Resource 8d), especially for loci Pd3-008, Pd11 and Pd13 315 for which $F_{S T}$ estimates exceed $0.250 * * *$ (Online Resource 8e). A pairwise $F_{S T}$ of $0.203 * * *$ was 316 calculated. At $K=3$, the allelic frequencies were less different (Online Resource 9d), and pairwise $317 F_{S T}$ varied from $0.117 * * *$ to $0.269 * * *$. Thus, considering the congruency among the five methods 318 (STRUCTURE, DAPC, MST, allelic frequencies and $F_{S T}$; Online Resources 6-9) within the four 319 datasets, the optimal $K$ was defined at 2. The two groups were designated SSH04a and SSH04b, and 
440 colonies $(96.1 \%)$ were assigned to a unique SSH $\left(P \geq 0.75 ; N_{S S H 04 a}=327 ; N_{S S H 04 b}=113 ;\right.$ Fig. 1 ;

321 Online Resource 4). SSH04a mainly regrouped colonies from Chesterfield Islands and western

322 Grande Terre, while SSH04b was composed of colonies from eastern Grande Terre and Loyalty

323 Islands (Fig. 2). However, the two SSHs were found in sympatry in eight sites (Fig. 1-2a).

324 Moreover, 18 colonies (3.9\%) were found admixed between the two SSHs: ten in Chesterfield

325 Islands (CHE01-02-04-05-10), six in Grande Terre (NCA02-03-05-07) and two in Loyalty Islands

326 (LOY02-03), but only four presented no missing data in their genotypes. Thus, these admixed

327 colonies probably correspond to bad assignments. Additionally, NEWHYBRIDS detected only six

328 hybrids among the 458 colonies (1.3\%; all F2), and almost all colonies ( 96\%) assigned to a SSH

329 were detected as pure lineages.

330 Then, assignment tests were performed using STRUCTURE and DAPC for each SSH

331 separately (Online Resource 10). For SSH04a, both methods were congruent only at $K=2$, and

332 retrieved the two groups previously found for the overall dataset at $K=3$ (Online Resource 10). As

333 previously, the MST was not congruent with STRUCTURE and DAPC (Online Resource 11), and a

334 pairwise $F_{S T}$ of $0.117 * * *$ was calculated between the two groups. As these two groups were already

335 found within the overall dataset, and as STRUCTURE and DAPC gave very similar results, we

336 considered that SSH04a was partitioned into two clusters, named SSH04a-1 and SSH04a-2. The

337 two clusters were found in sympatry in 11 sites, SSH04a-1 being the main cluster in Chesterfield

338 Islands, while SSH04a-2 being the most abundant in western Grande Terre $\left(N_{S S H O 4 a-1}=136\right.$; $N_{S S H 04 a-}$

$3392=119$; Fig. 1-2; Online Resource 4). However, both clusters had only three populations with

$340 N \geq 10$ over 23 and 13 for SSH04a-1 and SSH04a-2, respectively (Table 2; Online Resource 4). A

341 high proportion of the colonies $(22.0 \%)$ were found admixed between both clusters, within all

342 localities (CHE: 16.5\%; NCA: 23.5\%; LOY: 42.9\%), possibly due to bad assignments due to

343 missing data. Nevertheless, $41.7 \%$ of these admixed colonies were detected as F2 hybrids.

344 For SSH04b, STRUCTURE and DAPC were incongruent from $K=2$ (Online Resource 10).

345 Thus, SSH04b was considered to be composed of a unique cluster, mostly found in eastern Grande

346 Terre and Loyalty Islands. For this cluster, six populations over 11 had $N \geq 10$ (Table 2; Online

347 Resource 4). 
(a)

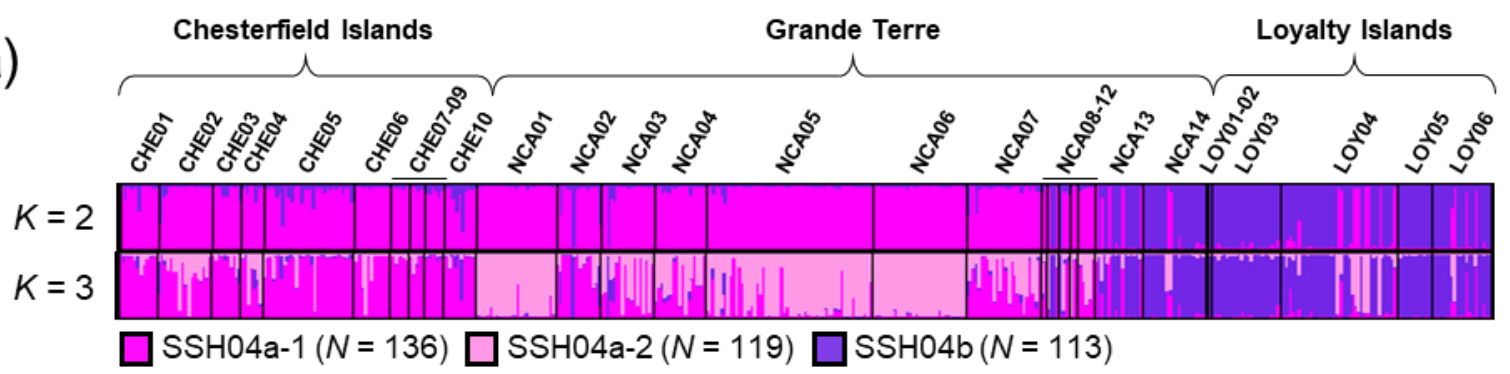

(c)

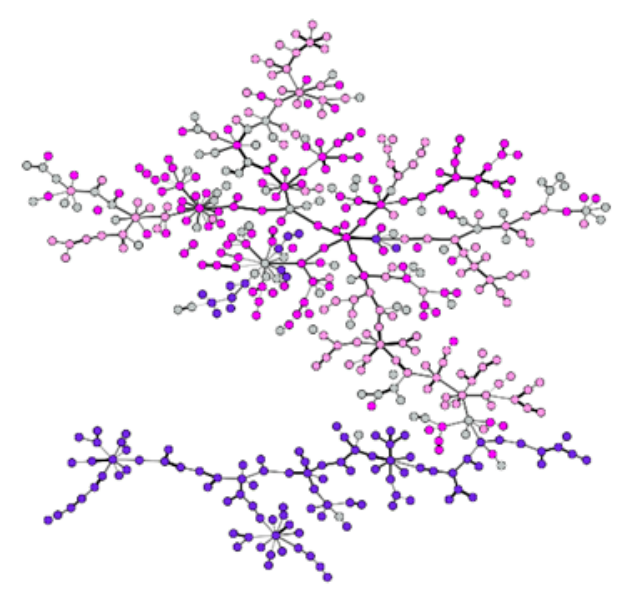

Fig. 2 Pocillopora PSH04 Secondary Species Hypotheses (SSHs) and clusters (Entire_11 dataset). (a) STRUCTURE plots at $K=2$ and $K=3$, (b) DAPC assignments for $K=3$ and (c) Minimum Spanning Tree. Colonies are coloured according to the clusters identified by STRUCTURE at $K=3$ (individual assignment probability $>0.75$ ). Colonies with an assignment probability inferior to 0.75 for each cluster were coloured in grey

\section{Genetic diversity and connectivity within each cluster}

Allelic diversity

At 11 loci, among populations with $N \geq 10$, the percentage of polymorphic loci $(P)$ varied from $73 \%$ for NCA02 $2_{S S H 04 a-1}$ to $100 \%$ for six populations. The percentage of missing data $\left(\% N A_{p o p}\right)$ ranged from $0.7 \%$ for NCA01 $\mathrm{ssH} 04 \mathrm{a}-2$ to $22.0 \%$ for LOY05 $\mathrm{ssH} 04 \mathrm{~b}$, the mean number of alleles per locus $\left(N a_{p o p} ; \pm \mathrm{SE}\right)$ varied from $2.6 \pm 0.3$ for LOY05 $\mathrm{SSH}_{04 \mathrm{~b}}$ to $4.8 \pm 0.8$ for CHE05 ${ }_{\mathrm{SSH} 04 \mathrm{a}-1}$, and the mean number of population-private alleles $\left(N p_{p o p} ; \pm \mathrm{SE}\right)$ varied from 0.0 for five populations to $0.3 \pm 0.1$ for LOY04 ssH04b. Population clonal richnesses were high, varying from 0.88 to 1.00 when considering missing data as different alleles, or from 0.77 to 1.00 when considering missing data as potentially identical alleles (Table 2). Thus, the mean observed and expected heterozygosities ( $H o_{p o p}$ and $H e_{p o p}$, respectively; $\pm \mathrm{SE}$ ) and $F_{I S}$ estimates were very similar between the entire and the truncated datasets. For the entire dataset (Entire_11), Hopop varied from $0.30 \pm 0.09$ for

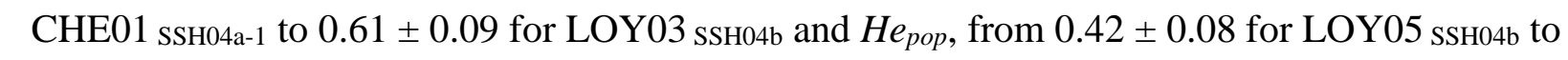
$0.58 \pm 0.04$ for LOY03 ssH04b. Almost all $F_{I S}$ estimates (11/12) were not significantly different from zero (ranging from $-0.10 \pm 0.16^{\mathrm{NS}}$ for LOY03 $\mathrm{SSH} 04 \mathrm{~b}$ to $0.22 \pm 0.09^{\mathrm{NS}}$ for NCA01 ssH04a-2), except in CHE01 ssH04a-1 $\left(F_{I S}=0.40 \pm 0.14 * *\right.$; Table 2$)$. All indices followed the same trends at 8 loci (Online Resource 12). 
Table 2 Pocillopora PSH04 population summary statistics at 11 loci. Only populations with at least 10 colonies were considered. Sites are detailed in Online Resource 4 . N: number of colonies; $N_{M L G}$ : number of multi-locus genotypes (MLGs) for both treatments of missing data; $R$ : clonal richness (Dorken and Eckert 2001); \%NA

$372 P$ : proportion of polymorphic loci; $N a_{p o p}$ and $N p_{p o p}$ : mean numbers $( \pm \mathrm{SE})$ of alleles and population-private alleles; $H o_{p o p}$ and $H e_{p o p}$ : mean ( \pm SE) observed and expected

373 heterozygosities and $F_{I S p o p}$ : mean $( \pm \mathrm{SE})$ inbreeding coefficient [Wright 1931 ; ${ }^{\mathrm{NS}}$ : non-significant $(P>0.05)$; **: $0.001<P<0.01$ ]

\begin{tabular}{|c|c|c|c|c|c|c|c|c|c|c|c|c|c|}
\hline \multirow{2}{*}{ Population } & \multirow{2}{*}{$N$} & \multirow{2}{*}{$N_{M L G}$} & \multirow{2}{*}{$\boldsymbol{R}$} & \multirow{2}{*}{$\% N A_{p o p}$} & & \multirow{2}{*}{$N a_{p o p}$} & \multirow{2}{*}{$N p_{p o p}$} & \multicolumn{3}{|c|}{ Entire_11 } & \multicolumn{3}{|c|}{ Truncated_11 } \\
\hline & & & & & & & & $H o_{p o p}$ & $\boldsymbol{H} \boldsymbol{e}_{p o p}$ & $F_{I S p o p}$ & Ho pop & $H e_{p o p}$ & $F_{\text {IS pop }}$ \\
\hline \multicolumn{14}{|l|}{$\overline{\text { SSH04a-1 }}$} \\
\hline & 11 & $10-11$ & $0.90-1.00$ & $0.3 \%$ & $91 \%$ & $3.1 \pm 0.5$ & $0.0 \pm 0.0$ & $0.30 \pm 0.09$ & $0.54 \pm 0.07$ & $0.40 \pm 0.14 * *$ & $0.30 \pm 0.08$ & $0.56 \pm 0.07$ & $0.40 \pm 0.14 *$ \\
\hline CHE05 & 21 & 21 & 1.00 & $6.9 \%$ & $100 \%$ & $4.8 \pm 0.8$ & $0.2 \pm 0.1$ & $0.40 \pm 0.09$ & $0.48 \pm 0.09$ & $0.12 \pm 0.07^{\mathrm{NS}}$ & $0.40 \pm 0.09$ & $0.48 \pm 0.09$ & $0.12 \pm 0.07^{\mathrm{NS}}$ \\
\hline NCA02 & 10 & $9-10$ & $0.89-1.00$ & $7.3 \%$ & $73 \%$ & $3.1 \pm 0.6$ & $0.1 \pm 0.1$ & $0.49 \pm 0.08$ & $0.56 \pm 0.07$ & $0.11 \pm 0.11^{\mathrm{NS}}$ & $0.45 \pm 0.07$ & $0.56 \pm 0.07$ & $0.15 \pm 0.11^{\mathrm{NS}}$ \\
\hline Total & 136 & $128-136$ & $0.94-1$ & & $0 \%$ & & & 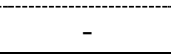 & - - - - & - & - & 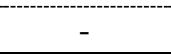 & 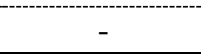 \\
\hline \multicolumn{14}{|l|}{ SSH04a-2 } \\
\hline NCA01 & 25 & 22 & 0.88 & & $100 \%$ & & $0.2 \pm 0.1$ & $0.36 \pm 0.07$ & $0.45 \pm 0.07$ & $0.22 \pm 0.09^{\mathrm{NS}}$ & $0.35 \pm 0.06$ & $0.46 \pm 0.07$ & $0.25 \pm 0.08 * *$ \\
\hline NCA05 & 42 & $39-42$ & $0.93-1.00$ & $9.2 \%$ & $100 \%$ & $3.9 \pm 0.5$ & $0.0 \pm 0.0$ & $0.38 \pm 0.08$ & $0.45 \pm 0.07$ & $0.10 \pm 0.12^{\mathrm{NS}}$ & $0.38 \pm 0.08$ & $0.45 \pm 0.07$ & $0.11 \pm 0.12^{\mathrm{NS}}$ \\
\hline NCA06 & 31 & $24-31$ & $0.77-1.00$ & $.3 \%$ & $91 \%$ & & $0.1 \pm 0.1$ & $0.41 \pm 0.10$ & $0.46 \pm 0.07$ & $0.11 \pm 0.13^{\mathrm{NS}}$ & $0.42 \pm 0.10$ & $0.48 \pm 0.07$ & $0.12 \pm 0.14^{\mathrm{NS}}$ \\
\hline Total & 119 & $106-116$ & $0.89-0.97$ & $8.3 \%$ & $100 \%$ & $5.2 \pm 0.8$ & & - & - & - & - & - & - \\
\hline \multicolumn{14}{|l|}{ SSH04b } \\
\hline NCA13 & 10 & & 1.00 & $2.7 \%$ & $100 \%$ & $3.1 \pm 0.3$ & $0.2 \pm 0.1$ & $0.45 \pm 0.08$ & $0.50 \pm 0.06$ & $0.08 \pm 0.17^{\mathrm{NS}}$ & $0.45 \pm 0.08$ & $0.50 \pm 0.06$ & $0.08 \pm 0.17^{\mathrm{NS}}$ \\
\hline NCA14 & 19 & $15-19$ & $0.78-1.00$ & $16.7 \%$ & $91 \%$ & $3.0 \pm 0.4$ & $0.0 \pm 0.0$ & $0.52 \pm 0.08$ & $0.48 \pm 0.05$ & $-0.09 \pm 0.14^{\mathrm{NS}}$ & $0.53 \pm 0.08$ & $0.50 \pm 0.05$ & $-0.09 \pm 0.14^{\mathrm{NS}}$ \\
\hline LOY03 & 23 & 22 & 0.95 & $10.7 \%$ & $100 \%$ & $3.4 \pm 0.6$ & $0.1 \pm 0.1$ & $0.61 \pm 0.08$ & $0.58 \pm 0.04$ & $-0.10 \pm 0.16^{\mathrm{NS}}$ & $0.61 \pm 0.08$ & $0.58 \pm 0.04$ & $-0.10 \pm 0.15^{\mathrm{NS}}$ \\
\hline LOY04 & 28 & $26-28$ & $0.93-1.00$ & $14.3 \%$ & $100 \%$ & $4.3 \pm 0.4$ & $0.3 \pm 0.1$ & $0.38 \pm 0.07$ & $0.45 \pm 0.04$ & $0.20 \pm 0.11^{\mathrm{NS}}$ & $0.39 \pm 0.07$ & $0.48 \pm 0.05$ & $0.22 \pm 0.10^{\mathrm{NS}}$ \\
\hline LOY05 & 12 & $10-12$ & $0.88-1.00$ & $22.0 \%$ & $82 \%$ & $2.6 \pm 0.3$ & $0.0 \pm 0.0$ & $0.40 \pm 0.11$ & $0.42 \pm 0.08$ & $0.09 \pm 0.17^{\mathrm{NS}}$ & $0.40 \pm 0.10$ & $0.45 \pm 0.08$ & $0.11 \pm 0.15^{\mathrm{NS}}$ \\
\hline LOY06 & 15 & 15 & 1.00 & $21.8 \%$ & $91 \%$ & $2.8 \pm 0.5$ & $0.0 \pm 0.0$ & $0.41 \pm 0.07$ & $0.47 \pm 0.06$ & $0.10 \pm 0.13^{\mathrm{NS}}$ & $0.40 \pm 0.07$ & $0.45 \pm 0.06$ & $0.09 \pm 0.12^{\mathrm{NS}}$ \\
\hline Total & 113 & $104-112$ & $0.92-0.99$ & $14.5 \%$ & $100 \%$ & $6.2 \pm 0.8$ & - & - & - & - & - & - & - \\
\hline Total PSH04 & 458 & $420-454$ & $0.92-0.99$ & $9.8 \%$ & $100 \%$ & $11.1 \pm 1.4$ & - & - & - & - & - & - & - \\
\hline
\end{tabular}


Genetic connectivity

376 At 11 loci, for the entire dataset (Entire_11), $F_{S T}$ estimates between intra-cluster pairs of 377 populations ranged from $0.025^{\mathrm{NS}}$ for NCA13/LOY06 (SSH04b) to $0.230 * * *$ for NCA14/LOY05 378 (SSH04b; mean $\pm \mathrm{SE}=0.118 \pm 0.137$ ), and $D_{\text {est }}$ estimates ranged from $0.009^{\mathrm{NS}}$ to $0.166^{* * *}$ for the 379 same population pairs (mean $\pm \mathrm{SE}=0.065 \pm 0.008$; Online Resource 13a). Estimates were generally 380 lower for the truncated dataset (Truncated_11: $0.028^{\mathrm{NS}}<F_{S T}<0.201 * * *$;

$\left.3810.009^{\mathrm{NS}}<D_{e s t}<0.163^{* * *}\right)$, but followed the same trends. For both datasets, genetic differentiation 382 between populations from different clusters was higher, with $F_{S T}$ ranging from $0.162 * * *$ to $3830.407 * * *$, and $D_{\text {est }}$ from $0.104 * * *$ to $0.448^{* * *}$ (Online Resource 13a). Again, at 8 loci, results were 384 very similar (Online Resource 13b).

385 The relative migration network retrieved the three clusters, but no particular pattern of 386 migration could be distinguished (Online Resource 14a), even when considering clusters separately 387 (Online Resource 14b), possibly due to the restricted size and number of populations. 388 Finally, population-based networks were built for each cluster independently. For SSH04a-1 389 and SSH04b, the Dpe was defined at 0.11, while it was higher for SSH04a-2 (Dpe = 0.64). Thus, all 390 networks were built at the $F_{S T}$ threshold of 0.11 (Fig. 3). The populations from SSH04a-2 and 391 SSH04b, almost all in eastern New Caledonia and Loyalty Islands, appeared weakly connected, 392 while those from SSH04a-1, located in Chesterfield Islands and New Caledonia (East and West) 393 were more connected (Fig. 3). 
(a)

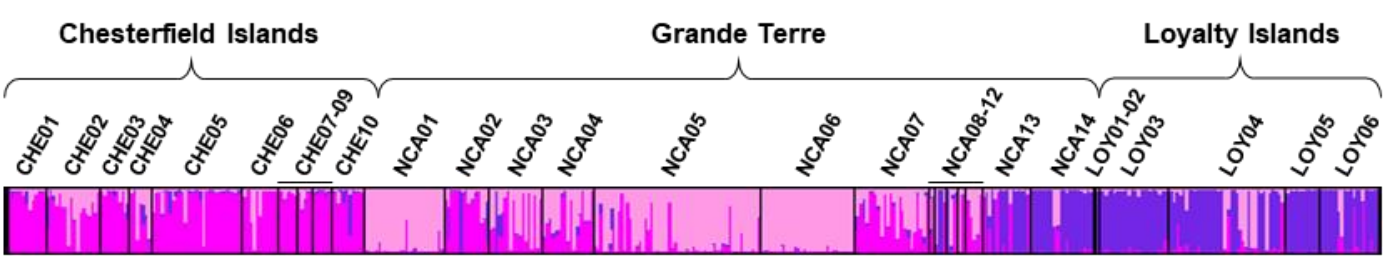

(b)

$\square$ SSH04a-1 ( $N=136) \square$ SSH04a-2 (N = 119) $\square$ SSH04b $(N=113)$

SSH04a-1 $(N=136 ; D p e=0.11)$
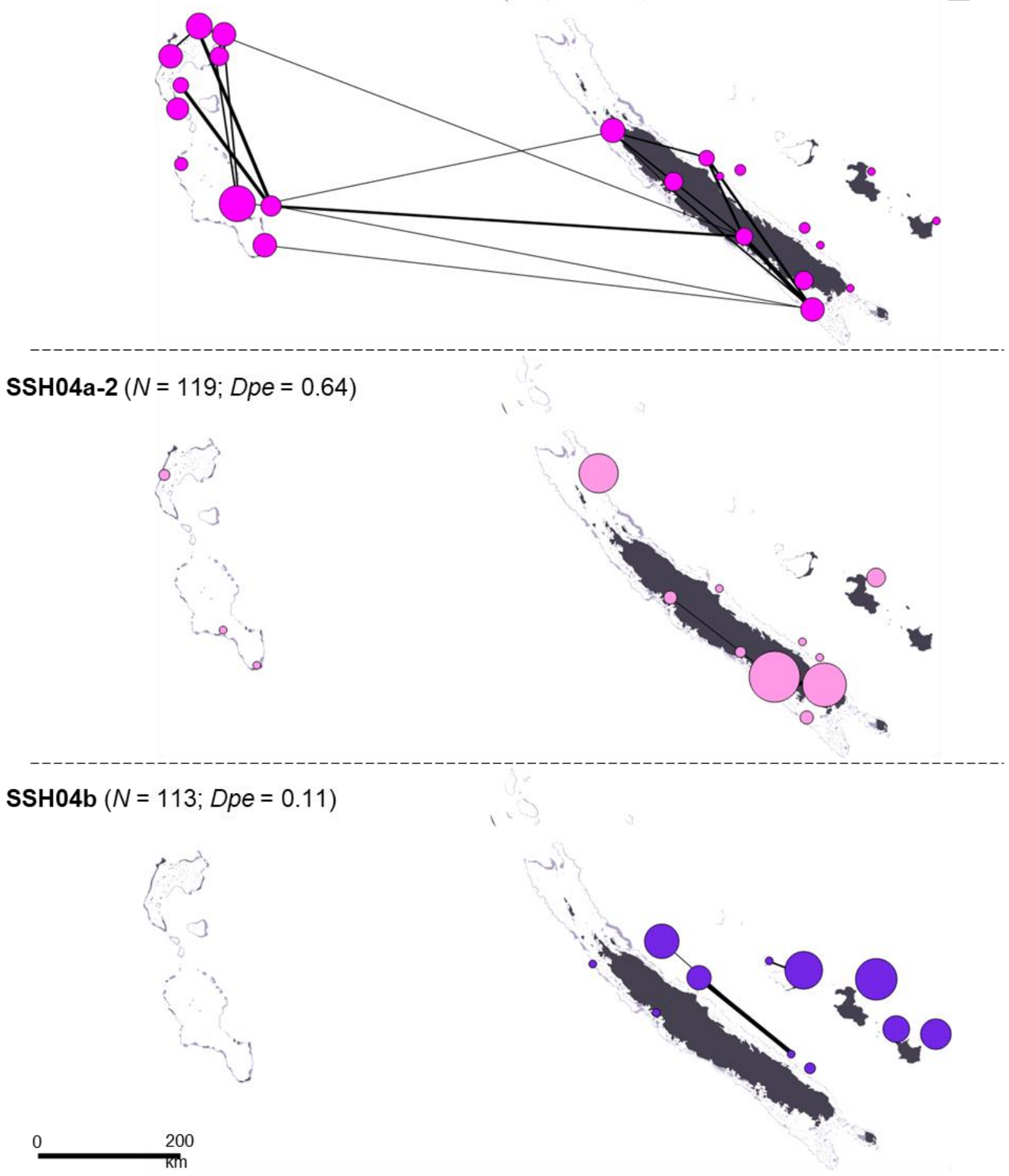

394 Fig. 3 Population-based networks for each cluster of Pocillopora PSH04 (Entire_11 dataset). (a) STRUCTURE plot at $395 K=3$, (b) population-based networks built with the $F_{S T}$ distance (Weir and Cockerham 1984) thresholded at 0.11 


\section{Discussion}

397 Our results evidenced that Pocillopora PSH04 colonies from the tropical southwestern Pacific 398 belong to two SSHs (SSH04a and SSH04b), found in sympatry among several sites. Moreover, 399 SSH04a split into two less differentiated clusters (SSH04a-1 and SSH04a-2), also sometimes 400 sympatric. This partitioning seems unrelated to corallum macromorphology (Online Resource 15), 401 nor clonality. Indeed, few repeated MLGs were detected among colonies, even when considering 402 missing data as potentially identical alleles, and results were very similar whether keeping them or 403 not. Finally, the studied populations appeared relatively differentiated (1) according to the relative 404 abundance of the different SSHs and clusters (the connectivity units), and (2) among each 405 connectivity unit, according to $F_{S T}$ and $D_{e s t}$ estimates.

\section{A single or several species?}

408 In this study, analysing the genetic partitioning within Pocillopora PSH04 using different assignment methods based on allelic frequencies or genetic distances estimated from microsatellite data, we found that colonies were divided into two divergent genetic groups (SSH04a and SSH04b), according to the congruence among the different methods used, and the different datasets analysed.

412 These two groups were strongly differentiated $\left(F_{S T}=0.203^{* * *}\right)$, especially for some loci, and seem 413 geographically separated (one SSH on each side of Grande Terre; Fig. 1). However, they were 414 found in sympatry in some sites. No distinction between the two SSHs based on corallum 415 macromorphology seems obvious (Online Resource 15). In addition, SSH04a was divided into two sympatric clusters (SSH04a-1 and SSH04a-2), which are themselves less, but still highly differentiated $\left(F_{S T}=0.117 * * *\right)$.

In a previous study (Gélin et al. 2017a), the species boundaries within the Pocillopora genus were redefined using species delimitation methods based on genetic information: 16 PSHs were defined within the genus, some of which splitting into several SSHs. For example, Pocillopora PSH05 (sensu Gélin et al. 2017a), corresponding to P. acuta (previously P. damicornis $\beta$ ), split into four SSHs (SSH05a, b, c and d), SSH05a and SSH05b being in sympatry in the Pacific Ocean, and SSH05c and SSH05d in the Indian Ocean (Gélin et al. 2018b). However, no genetic partitioning was previously identified within Pocillopora PSH04, as the former analyses were conducted on colonies belonging to the entire genus ( $N=975$ colonies of which 102 were assigned to Pocillopora PSH04, more precisely to SSH04a), and each locality was represented by only few colonies (Gélin et al. 2017a). In the present study, only colonies assigned to Pocillopora PSH04 were considered, representing a small proportion of the diversity of the genus, but a larger number of colonies per locality. 
Discoveries of cryptic species are not rare within scleractinian corals. Indeed, many species were defined on the sole use of traditional taxonomic (often morphological) characters (see Veron 2000), which are ambiguous due to phenotypic plasticity. Thus, many morphospecies previously thought to be distributed in the whole Indo-Pacific, were in fact complexes of different species, each restricted to the ocean basin [e.g. P. damicornis (Schmidt-Roach et al. 2014), P. eydouxi/meandrina (Gélin et al. 2018a), P. verrucosa (Oury et al. submitted), Stylophora pistillata (Keshavmurthy et al. 2013), Leptastrea pruinosa (Arrigoni et al. 2020)]. Sympatric cryptic coral species are not unusual too. For example, four sympatric clusters were found within Seriatopora hystrix colonies from Lizard and Palm Islands (GBR; Warner et al. 2015), three in the Ryūkyū Archipelago (Japan; Nakajima et al. 2017). Misidentifying these cryptic species implies many consequences, such as incorrect biodiversity and connectivity assessments, themselves influencing the implementation of management and conservation plans.

In a previous study, Thomas et al. (2014) showed, using six microsatellite markers, that P. damicornis s.s. colonies of Ningaloo Reef and Muiron Islands (western Australia) belong to two distinct genetic clusters, one in the North of the sampling area, the other in the South, and in sympatry only at intermediate latitude sites. This pattern of genetic structuring is similar to the one observed by Gélin et al. (2017b), studying several populations of Pocillopora SSH05c in Reunion Island (southwestern Indian Ocean). A geographic barrier or asynchronous spawning of the most distant populations were mentioned to explain this pattern (Gélin et al. 2017b). A similar pattern was also observed within colonies of Acropora tenuis from Nansei Islands (Japan), suggesting the existence of two source populations at the geographic extremities of the sampling area, both mixing within the intermediate populations (Zayasu et al. 2016). In the present study, if the two SSHs, or the three clusters, constitute evolutionary units or distinct species, then reproductive barriers probably established among them. Ecological gradients, such as depth, were already evoked to explain the sympatry of Seriatopora hystrix clusters in the Ryūkyū Archipelago (Flot et al. 2008; Bongaerts et al. 2010; van Oppen et al. 2011; Nakajima et al. 2017). The same would apply to Porites astreoides (Lamarck, 1816) in Florida (southeastern USA; Serrano et al. 2016). However, depth does not appear to be the reproductive barrier here, as colonies sampled on a same site were usually at the same depth: all $P$. damicornis s.s. colonies were sampled in lagoons and upper reef slopes, between sea surface and $5 \mathrm{~m}$ depth. However differential habitats on both sides of Grande Terre could explain the SSHs. Indeed, in the GBR, differences in habitat specificity were found among Seriatopora hystrix cryptic species, some being restricted to sheltered reefs, while others to exposed reefs (Warner et al. 2015). A similar trend could be hypothesised here, with SSH04a being mainly found in large and relatively sheltered lagoons (Chesterfield Islands and western Grande Terre), while SSH04b in more exposed habitats (eastern Grande Terre and Loyalty Islands; Fig. 1). 
466 Clonality or not clonality?

467 Among the 458 colonies studied, only two MLGs were found repeated within sympatric colonies

$468(R=0.99)$ when considering all 11 loci and missing data as different alleles. The clonality increased 469 when considering missing data as potentially identical alleles, but remained weak (27 MLGs 470 repeated over 458 colonies; $R=0.92 ; 330-389$ MLLs). At 8 loci, clonal richness was lower $(R$ 471 between 0.93 and 0.86 , considering missing data as different or potentially identical alleles, 472 respectively; 161-265 MLLs), but colonies sharing the same MLG at 8 loci had distinct MLGs at 11 473 loci. Moreover, high $P_{\mathrm{SEX}}\left(F_{I S}\right)$ values and colonies sharing identical MLGs distant from more than $474750 \mathrm{~km}$ suggest an underestimation of the clonal richness at 8 loci. This relatively low rate of 475 clonality can be explained by a non-optimal sampling to detect clonality (unlike random sampling 476 for example). Nevertheless, with the same sampling (except in Reunion Island), Gélin et al. (2018b) 477 found a high clonality rate in Pocillopora PSH05 [819 distinct MLGs (668-794 MLLs) among $4781,418$ colonies over 13 loci, including the 11 ones from the present study; $R=0.577]$. Thus, 479 although the sampling was not appropriate for the study of clonality, if asexual propagation was 480 common such as in Pocillopora PSH05, then a higher clonality rate should have been observed. In other genetic studies focusing on P. damicornis s.s., clonality rates were higher. Using six microsatellite loci, Thomas et al. (2014) obtained a global clonal richness of $0.52(N=162$ colonies) but with a high spatial variability ( $R$ varying from 0.15 to 0.87 per site). Some MLGs were highly represented (up to 13 colonies sharing the same MLG) and others present in several sites (three MLGs present in two sites and one in three sites, distant from 6 to $240 \mathrm{~km}$; Thomas et al. 2014). Same trends were found by Torda et al. (2013a, b) in the GBR region, using nine microsatellite loci. These differences in clonality rates could results from the lower number of loci used in previous studies (and from their low polymorphism and/or possible homoplasy). It could also be the result of a spatial variation in clonal propagation within P. damicornis s.s. (e.g. due to different hurricane frequencies favouring fragmentation), or the result of differences in clonal propagation between cryptic species. As an illustration, Porites lobata colonies from the eastern tropical Pacific were disentangled in two species: Porites lobata, which reproduces mainly sexually, and Porites evermanni, which propagates through fragmentation by triggerfishes (Boulay et al. 2014). Different clonality rates were also found between western and eastern Caribbean Acropora palmata populations, possibly related to habitat characteristics (Baums et al. 2006). Whatever the cause of these differences, clonal propagation in P. damicornis s.s. populations from New

\section{Weak connectivity in New Caledonia}


500 Considering the clusters as connectivity units, some populations, sometimes relatively distant (e.g.

501 NCA13 and LOY06 within SSH04b, 340 km apart), were genetically undifferentiated, while

502 some populations belonging to the same locality, or even neighbours (i.e. a few tens kilometres 503 apart), were highly differentiated. Such pattern could be a consequence of the restricted size and 504 number of populations within each cluster (due to cryptic species), or suggests that population differentiation is not entirely related to geographic distance (isolation by distance hypothesis could not be tested). Currents could also be involved, as water exchanges between Grande Terre lagoons and the open ocean are weak and regional currents are dominated by a flow from East to West, resulting from the southeastern trade winds (Fig. 1; Vega et al. 2006). This suggests the existence of two reef systems hydrologically isolated on both sides of Grande Terre. Accordingly, populations of eastern Grande Terre (sinks) would be connected to Loyalty Islands populations (sources) by a unidirectional gene flow from East to West, following currents. Grande Terre would act as a geographical barrier for this flow, explaining why SSH04a-2 and SSH04b are almost restricted to the East of the ecoregion. However, it is conceivable that gene flow from eastern Grande Terre or 514 Loyalty Islands will persist and reach Chesterfield Islands either directly through surface currents 515 bypassing Grande Terre from the North, or indirectly through intermediate population(s) (stepping stone colonization). Unfortunately, we were unable to confirm this pattern of migration from the relative migration networks, again possibly due to the size and number of populations.

A high genetic differentiation was also observed between four Pocillopora PSH05 (P. acuta) populations from Grande Terre (corresponding to NCA01, NCA03, NCA05-06 and NCA11 herein; Gélin et al. 2018b). In addition, Postaire et al. (2017) showed a strong genetic differentiation between populations of the hydrozoan Macrorhynchia phoenicea $\alpha$ (sensu Postaire et al. 2016) in Chesterfield Islands, Grande Terre and Loyalty Islands (many sites in common with this study), explained by the ecology of this species, often found attached at the base of Pocillopora colonies, although presenting a medusoid phase. Similar results were obtained from three new caledonian populations (close from NCA02, NCA05-06 and NCA10 herein) of two reef fishes: Acanthurus triostegus (larval stage duration: $60 \mathrm{~d}$ ) and Stegastes nigricans (24 d; Planes et al. 1998). In contrast, the same three populations of another reef fish, Epinephelus merra (39 d), were found weakly differentiated in the same study (Planes et al. 1998). This difference was explained by 529 (1) a limited sampling and (2) the high migratory capabilities of E. merra adults during spawning. 530 Nevertheless, although several studies have revealed a weak connectivity in this ecoregion, the 531 pattern seems not generalizable to all species. Indeed, using the mitochondrial COI, a high connectivity was found within populations of four squat lobster-like and a gastropod species from Isle of Pines and Norfolk seamounts (southern of Grande Terre; Samadi et al. 2006). It is thus 
necessary to multiply genetic connectivity investigations in this under-studied Pacific region to achieve accurate multi-specific models.

\section{Conclusion}

Our results provide insights on the genetic diversity, structure, and connectivity of populations of Pocillopora damicornis s.s., a recently delimited Pocillopora species that is thus largely understudied. In addition, this study focused on a marine province located in the South of the distribution range of this species: the tropical southwestern Pacific, largely understudied as well. Thus, several evolutionary units, perhaps even several species, are distinguished under the name of Pocillopora damicornis s.s. Nevertheless, focusing on each evolutionary unit, their populations from the tropical southwestern Pacific appeared differentiated, probably due to restricted gene flow, limited by currents, habitat specificities and/or geographical distances among populations. This low connectivity between populations, coupled with the existence of cryptic species, brings new insights to the connectivity pattern of New Caledonia ecoregion. Such results must be considered for setting up appropriate management plans for the Natural Park of the Coral Sea.

Acknowledgements Coral sampling in New Caledonia (HM) was carried out during COBELO (doi: http://dx.doi.org/10.17600/13100100), BIBELOT (http://dx.doi.org/10.17600/14003700), and CHEST (http://dx.doi.org/10.17600/15004500) oceanographic campaigns on board of RV Alis (IRD), and in the North-East and North-West of Madagascar during MAD (http://dx.doi.org/10.17600/16004700) oceanographic campaign on board of RV Antea (IRD). Sampling in Reunion Island (HM, PG) was supported by program CONPOCINPA (LabEx CORAIL fund); in the South of Madagascar (HM) in collaboration with the Institut Halieutique des Sciences Marines (Tulear) and in Rodrigues Island (HM) with the collaboration of the Rodrigues Regional Assembly and the South-East Marine Protected Area supported by project Biodiversity (POCT FEDER fund); in Europa, Juan de Nova and Glorioso Islands (HM) by program BIORECIE (financial supports from INEE, INSU, IRD, AAMP, FRB, TAAF, and the foundation Veolia Environnement); in Tromelin Island (HM) by program ORCIE (INEE), and in Mayotte (HM) by program SIREME (FED). HM thanks all the buddies who helped in photographs during diving (J. Butscher, S. Andréfouët, L. Bigot, M. Pinault). We acknowledge the Plateforme Gentyane of the Institut National de la Recherche Agronomique (INRA, Clermont-Ferrand, France) for genotyping and technical support. PG and NO were respectively financially supported by PhD contracts from the LabEx CORAIL and the Doctoral School of Reunion Island University. We thank the reviewers for their comments to improve the manuscript. 


\section{Declarations}

$570 \quad$ Funding Not applicable.

571 Conflict of interest/Competing interests The authors declare that they have no conflict of interest.

572 Ethics approval All applicable international, national and/or institutional guidelines for sampling,

573 care and experimental use of organisms for the study have been followed and all necessary

574 approvals have been obtained (New Caledonia ecoregion: authorizations $n^{\circ} 2432-2012 / A R R / D E N V$,

$575 \mathrm{n}^{\circ}$ 2660-2013/ARR/DENV, ${ }^{\circ}$ 60912-25-28-2012/JJC, ${ }^{\circ}{ }^{\circ} 60455-15-25 / J J C$ and $\left.{ }^{\circ} 6161-37 / P R\right)$.

576 Consent to participate Not applicable.

577 Consent for publication Not applicable.

578 Availability of data and material Data are deposited on Zenodo: http://doi.org/XXXXXX

579 Code availability Not applicable.

580 Author's contributions HM collected samples. NO, PG and HM did lab steps and analysed the

581 genotyping results. NO wrote the original draft and NO, PG and HM reviewed and edited the

582 manuscript.

\section{References}

585

586

587

588

589

590

591

592

593

594

595

596

597

598

599

600

601

602

603

604

605

606

607

608

609

610

611

Alberto F, Gouveia L, Arnaud-Haond S, Pérez-Lloréns JL, Duarte CM, Serrao EA (2005) Withinpopulation spatial genetic structure, neighbourhood size and clonal subrange in the seagrass Cymodocea nodosa. Mol Ecol 14:2669-2681. doi: 10.1111/j.1365-294X.2005.02640.x

Anderson EC, Thompson EA (2002) A model-based method for identifying species hybrids using multilocus genetic data. Genetics 160:1217-1229.

Arnaud-Haond S, Belkhir K (2007) GENCLONE: a computer program to analyse genotypic data, test for clonality and describe spatial clonal organization. Mol Ecol Notes 7:15-17. doi: 10.1111/j.1471-8286.2006.01522.x

Arnaud-Haond S, Duarte CM, Alberto F, Serrão EA (2007) Standardizing methods to address clonality in population studies. Mol Ecol 16:5115-5139. doi: 10.1111/j.1365294X.2007.03535.X

Arrigoni R, Berumen ML, Mariappan KG, Beck PSA, Hulver AM, Montano S, Pichon M, Strona G, Terraneo TI, Benzoni F (2020) Towards a rigorous species delimitation framework for scleractinian corals based on RAD sequencing: the case study of Leptastrea from the IndoPacific. Coral Reefs. doi: 10.1007/s00338-020-01924-8

Balloux F, Lehmann L, de Meeûs T (2003) The population genetics of clonal and partially clonal diploids. Genetics 164:1635-1644.

Baums IB, Miller MW, Hellberg ME (2006) Geographic variation in clonal structure in a reefbuilding Caribbean coral, Acropora palmata. Ecol Monogr 76:503-519. doi: 10.1890/00129615(2006)076[0503:GVICSI]2.0.CO;2

Bickford D, Lohman DJ, Sodhi NS, Ng PKL, Meier R, Winker K, Ingram KK, Das I (2007) Cryptic species as a window on diversity and conservation. Trends Ecol Evol 22:148-155. doi: 10.1016/j.tree.2006.11.004

Bongaerts P, Riginos C, Ridgway T, Sampayo EM, van Oppen MJH, Englebert N, Vermeulen F, Hoegh-Guldberg O (2010) Genetic divergence across habitats in the widespread coral Seriatopora hystrix and its associated Symbiodinium. PLoS ONE 5:e10871. doi: 10.1371/journal.pone.0010871 
Boulay JN, Hellberg ME, Cortés J, Baums IB (2014) Unrecognized coral species diversity masks differences in functional ecology. Proc R Soc B Biol Sci 281:20131580. doi: 10.1098/rspb.2013.1580

Bowen BW, Rocha LA, Toonen RJ, Karl SA (2013) The origins of tropical marine biodiversity. Trends Ecol Evol 28:359-366. doi: 10.1016/j.tree.2013.01.018

Cowen RK, Sponaugle S (2009) Larval dispersal and marine population connectivity. Annu Rev Mar Sci 1:443-466. doi: 10.1146/annurev.marine.010908.163757

Cowen RK, Gawarkiewicz G, Pineda J, Thorrold SR, Werner F (2003) Population connectivity in marine systems. Report of a workshop to develop science recommendations for the National Science Foundation. EOS Trans 84:119-119.

Cuif M, Kaplan DM, Lefèvre J, Faure VM, Caillaud M, Verley P, Vigliola L, Lett C (2014) Windinduced variability in larval retention in a coral reef system: A biophysical modelling study in the South-West Lagoon of New Caledonia. Prog Oceanogr 122:105-115. doi: 10.1016/j.pocean.2013.12.006

Dorken ME, Eckert CG (2001) Severely reduced sexual reproduction in northern populations of a clonal plant, Decodon verticillatus (Lythraceae). J Ecol 89:339-350. doi: 10.1046/j.13652745.2001.00558.x

Drechsler M, Frank K, Hanski I, O’Hara RB, Wissel C (2003) Ranking metapopulation extinction risk: from patterns in data to conservation management decisions. Ecol Appl 13:990-998. doi: 10.1890/1051-0761(2003)13[990:RMERFP]2.0.CO;2

Fišer C, Robinson CT, Malard F (2018) Cryptic species as a window into the paradigm shift of the species concept. Mol Ecol 27:613-635. doi: 10.1111/mec.14486

Flot J-F, Licuanan WY, Nakano Y, Payri C, Cruaud C, Tillier S (2008) Mitochondrial sequences of Seriatopora corals show little agreement with morphology and reveal the duplication of a tRNA gene near the control region. Coral Reefs 27:789-794. doi: 10.1007/s00338-008-04072

Forsman Z, Wellington GM, Fox GE, Toonen RJ (2015) Clues to unraveling the coral species problem: distinguishing species from geographic variation in Porites across the Pacific with molecular markers and microskeletal traits. PeerJ 3:e751. doi: 10.7717/peerj.751

Gélin P, Postaire B, Fauvelot C, Magalon H (2017a) Reevaluating species number, distribution and endemism of the coral genus Pocillopora Lamarck, 1816 using species delimitation methods and microsatellites. Mol Phylogenet Evol 109:430-446. doi: 10.1016/j.ympev.2017.01.018

Gélin P, Fauvelot C, Mehn V, Bureau S, Rouzé H, Magalon H (2017b) Superclone expansion, longdistance clonal dispersal and local genetic structuring in the coral Pocillopora damicornis type $\beta$ in Reunion Island, South Western Indian Ocean. PLoS ONE 12:e0169692. doi: 10.1371/journal.pone.0169692

Gélin P, Fauvelot C, Bigot L, Baly J, Magalon H (2018a) From population connectivity to the art of striping Russian dolls: the lessons from Pocillopora corals. Ecol Evol 8:1411-1426. doi: 10.1002/ece3.3747

Gélin P, Pirog A, Fauvelot C, Magalon H (2018b) High genetic differentiation and low connectivity in the coral Pocillopora damicornis type $\beta$ at different spatial scales in the Southwestern Indian Ocean and the Tropical Southwestern Pacific. Mar Biol 165-167. doi: 10.1007/s00227018-3428-6

Goudet J (2001) FSTAT, a program to estimate and test gene diversities and fixation indices version 2.9.3.2, updated from Goudet 1995.

Halkett F, Simon J-C, Balloux F (2005) Tackling the population genetics of clonal and partially clonal organisms. Trends Ecol Evol 20:194-201. doi: 10.1016/j.tree.2005.01.001

Harii S, Kayanne H, Takigawa H, Hayashibara T, Yamamoto M (2002) Larval survivorship, competency periods and settlement of two brooding corals, Heliopora coerulea and Pocillopora damicornis. Mar Biol 141:39-46. doi: 10.1007/s00227-002-0812-y

Harrison PL (2011) Sexual reproduction of scleractinian corals. In: Dubinsky Z, Stambler N (eds) Coral reefs: an ecosystem in transition. Springer, Dordrecht, pp 59-85 
Hatcher BG (1990) Coral reef primary productivity. A hierarchy of pattern and process. Trends Ecol Evol 5:149-155. doi: 10.1016/0169-5347(90)90221-X

Highsmith RC (1982) Reproduction by fragmentation in corals. Mar Ecol Prog Ser 7:207-226. doi: 10.3354/meps007207

Hughes TP, Bellwood DR, Baird AH, Brodie J, Bruno JF, Pandolfi JM (2011) Shifting base-lines, declining coral cover, and the erosion of reef resilience: comment on Sweatman et al. (2011). Coral Reefs 30:653-660. doi: 10.1007/s00338-011-0787-6

Jombart T, Devillard S, Balloux F (2010) Discriminant analysis of principal components: a new method for the analysis of genetically structured populations. BMC Genet 11:94. doi: 10.1186/1471-2156-11-94

Jost LOU (2008) GST and its relatives do not measure differentiation. Mol Ecol 17:4015-4026. doi: 10.1111/j.1365-294X.2008.03887.x

Keenan K, McGinnity P, Cross TF, Crozier WW, Prodöhl PA (2013) diversity : an R package for the estimation and exploration of population genetics parameters and their associated errors. Methods Ecol Evol 4:782-788. doi: 10.1111/2041-210X.12067

Keshavmurthy S, Yang S-Y, Alamaru A, Chuang Y-Y, Pichon M, Obura D, Fontana S, De Palmas S, Stefani F, Benzoni F, MacDonald A, Noreen AME, Chen C, Wallace CC, Pillay RM, Denis V, Amri AY, Reimer JD, Mezaki T, Sheppard C, Loya Y, Abelson A, Mohammed MS, Baker AC, Mostafavi PG, Suharsono BA, Chen CA (2013) DNA barcoding reveals the coral "laboratory-rat", Stylophora pistillata encompasses multiple identities. Sci Rep 3:1520. doi: 10.1038/srep01520

Kivelä M, Arnaud-Haond S, Saramäki J (2015) EDENetworks: a user-friendly software to build and analyse networks in biogeography, ecology and population genetics. Mol Ecol Resour 15:117-122. doi: 10.1111/1755-0998.12290

Knowlton N (1993) Sibling species in the sea. Annu Rev Ecol Syst 24:189-216. doi: 10.1146/annurev.es.24.110193.001201

Marti-Puig P, Forsman ZH, Haverkort-Yeh RD, Knapp IS, Maragos JE, Toonen RJ (2014) Extreme phenotypic polymorphism in the coral genus Pocillopora; micro-morphology corresponds to mitochondrial groups, while colony morphology does not. Bull Mar Sci 90:211-231. doi: $10.5343 / \mathrm{bms} .2012 .1080$

Mayr E (1963) Animal species and evolution. Harvard University Press

Meirmans PG, van Tienderen PH (2004) GENOTYPE and GENODIVE: two programs for the analysis of genetic diversity of asexual organisms. Mol Ecol Notes 4:792-794. doi: 10.1111/j.14718286.2004.00770.x

Mills LS, Allendorf FW (1996) The one-migrant-per-generation rule in conservation and management. Conserv Biol 10:1509-1518. doi: 10.1046/j.1523-1739.1996.10061509.x

Mönkkönen M, Reunanen P (1999) On critical thresholds in landscape connectivity: a management perspective. Oikos 84:302-305.

Nakajima Y, Nishikawa A, Iguchi A, Nagata T, Uyeno D, Sakai K, Mitarai S (2017) Elucidating the multiple genetic lineages and population genetic structure of the brooding coral Seriatopora (Scleractinia: Pocilloporidae) in the Ryukyu Archipelago. Coral Reefs 36:415-426. doi: 10.1007/s00338-017-1557-x

Oury N, Gélin P, Magalon H (submitted) From striping Russian dolls to clarifying the myth of IndoPacific coral species: high connectivity within restricted distribution range in Pocillopora genus. J Biogeogr

Palumbi SR (1992) Marine speciation on a small planet. Trends Ecol Evol 7:114-118. doi: 10.1016/0169-5347(92)90144-Z

Pante E, Puillandre N, Viricel A, Arnaud-Haond S, Aurelle D, Castelin M, Chenuil A, Destombe C, Forcioli D, Valero M, Viard F, Samadi S (2015) Species are hypotheses: avoid connectivity assessments based on pillars of sand. Mol Ecol 24:525-544. doi: 10.1111/mec.13048 
Paulay G, Meyer C (2002) Diversification in the tropical Pacific: comparisons between marine and terrestrial systems and the importance of founder speciation. Integr Comp Biol 42:922-934. doi: $10.1093 / \mathrm{icb} / 42.5 .922$

Pinzón JH, Sampayo E, Cox E, Chauka LJ, Chen CA, Voolstra CR, LaJeunesse TC (2013) Blind to morphology: genetics identifies several widespread ecologically common species and few endemics among Indo-Pacific cauliflower corals (Pocillopora, Scleractinia). J Biogeogr 40:1595-1608. doi: 10.1111/jbi.12110

Planes S, Parroni M, Chauvet C (1998) Evidence of limited gene flow in three species of coral reef fishes in the lagoon of New Caledonia. Mar Biol 130:361-368. doi: 10.1007/s002270050256

Postaire B, Magalon H, Bourmaud CA-F, Bruggemann JH (2016) Molecular species delimitation methods and population genetics data reveal extensive lineage diversity and cryptic species in Aglaopheniidae (Hydrozoa). Mol Phylogenet Evol 105:36-49. doi: 10.1016/j.ympev.2016.08.013

Postaire B, Gélin P, Bruggemann JH, Pratlong M, Magalon H (2017) Population differentiation or species formation across the Indian and the Pacific Oceans? An example from the brooding marine hydrozoan Macrorhynchia phoenicea. Ecol Evol 7:8170-8186. doi: 10.1002/ece 3.3236

Pritchard JK, Stephens M, Donnelly P (2000) Inference of population structure using multilocus genotype data. Genetics 155:945-959.

R Core Team (2016) R: a language and environment for statistical computing. R Foundation for Statistical Computing, Vienna, Austria. URL: https://www.R-project.org/

Raymond M, Rousset F (1995) GENEPOP: Population genetics software for exact tests and ecumenism. J Hered 86:248-249. doi: 10.1111/j.1558-5646.1995.tb04456.x

Richmond RH (1987) Energetics, competency, and long-distance dispersal of planula larvae of the coral Pocillopora damicornis. Mar Biol 93:527-533. doi: 10.1007/BF00392790

Rousset F (2008) Genepop'007: a complete re-implementation of the genepop software for Windows and Linux. Mol Ecol Resour 8:103-106. doi: 10.1111/j.1471-8286.2007.01931.x

Rozenfeld AF, Arnaud-Haond S, Hernández-García E, Eguíluz VM, Matías MA, Serrão E, Duarte CM (2007) Spectrum of genetic diversity and networks of clonal organisms. J R Soc Interface 4:1093-1102. doi: 10.1098/rsif.2007.0230

Samadi S, Bottan L, Macpherson E, De Forges BR, Boisselier M-C (2006) Seamount endemism questioned by the geographic distribution and population genetic structure of marine invertebrates. Mar Biol 149:1463-1475. doi: 10.1007/s00227-006-0306-4

Schmidt-Roach S, Lundgren P, Miller KJ, Gerlach G, Noreen AME, Andreakis N (2012a) Assessing hidden species diversity in the coral Pocillopora damicornis from Eastern Australia. Coral Reefs 32:161-172. doi: 10.1007/s00338-012-0959-z

Schmidt-Roach S, Miller KJ, Woolsey E, Gerlach G, Baird AH (2012b) Broadcast spawning by Pocillopora species on the Great Barrier Reef. PLoS ONE 7:e50847. doi: 10.1371/journal.pone.0050847

Schmidt-Roach S, Miller KJ, Lundgren P, Andreakis N (2014) With eyes wide open: a revision of species within and closely related to the Pocillopora damicornis species complex (Scleractinia; Pocilloporidae) using morphology and genetics. Zool J Linn Soc 170:1-33. doi: 10.1111/zoj.12092

Serrano XM, Baums IB, Smith TB, Jones RJ, Shearer TL, Baker AC (2016) Long distance dispersal and vertical gene flow in the Caribbean brooding coral Porites astreoides. Sci Rep 6:21619. doi: 10.1038/srep21619

Spalding MD, Fox HE, Allen GR, Davidson N, Ferdaña ZA, Finlayson MAX, Halpern BS, Jorge MA, Lombana AL, Lourie SA (2007) Marine ecoregions of the world: a bioregionalization of coastal and shelf areas. BioScience 57:573-583. doi: 10.1641/b570707

Stoddart JA (1983) Asexual production of planulae in the coral Pocillopora damicornis. Mar Biol 76:279-284. doi: 10.1007/BF00393029 
Sundqvist L, Keenan K, Zackrisson M, Prodöhl P, Kleinhans D (2016) Directional genetic differentiation and relative migration. Ecol Evol 6:3461-3475. doi: 10.1002/ece3.2096

Thomas L, Kendrick GA, Stat M, Travaille KL, Shedrawi G, Kennington WJ (2014) Population genetic structure of the Pocillopora damicornis morphospecies along Ningaloo Reef, Western Australia. Mar Ecol Prog Ser 513:111-119. doi: 10.3354/meps10893

Todd PA (2008) Morphological plasticity in scleractinian corals. Biol Rev 83:315-337. doi: 10.1111/j.1469-185X.2008.00045.X

Torda G, Lundgren P, Willis BL, van Oppen MJH (2013a) Genetic assignment of recruits reveals short-and long-distance larval dispersal in Pocillopora damicornis on the Great Barrier Reef. Mol Ecol 22:5821-5834. doi: 10.1111/mec.12539

Torda G, Lundgren P, Willis BL, van Oppen MJH (2013b) Revisiting the connectivity puzzle of the common coral Pocillopora damicornis. Mol Ecol 22:5805-5820. doi: 10.1111/mec.12540

van Oosterhout C, Hutchinson WF, Wills DP, Shipley P (2004) Micro-CHECKER: software for identifying and correcting genotyping errors in microsatellite data. Mol Ecol Notes 4:535538. doi: 10.1111/j.1471-8286.2004.00684.x

van Oppen MJH, Bongaerts P, Underwood JN, Peplow LM, Cooper TF (2011) The role of deep reefs in shallow reef recovery: an assessment of vertical connectivity in a brooding coral from west and east Australia. Mol Ecol 20:1647-1660. doi: 10.1111/j.1365-294X.2011.05050.x

Vega A, Marchesiello P, Lefêvre J (2006) Atlas hydrodynamique de la Zone Economique Exclusive de la Nouvelle-Calédonie. Laboratoire d'Etudes Géophysiques et d'Océanographie Spatiale, Nouméa, Nouvelle-Calédonie

Veron JEN (2000) Corals of the world. Australian Institute of Marine Science, Australia

Warner PA, van Oppen MJH, Willis BL (2015) Unexpected cryptic species diversity in the widespread coral Seriatopora hystrix masks spatial-genetic patterns of connectivity. Mol Ecol 24:2993-3008. doi: 10.1111/mec.13225

Weir BS, Cockerham CC (1984) Estimating F-statistics for the analysis of population structure. Evolution 38:1358-1370. doi: 10.1111/j.1558-5646.1984.tb05657.x

Wilkinson CR (2008) Status of coral reefs of the world: 2008. Global Coral Reef Monitoring Network and Reef and Rainforest Research Centre, Townsville, Australia

Wright S (1931) Evolution in Mendelian populations. Genetics 16:97-159.

Zayasu Y, Nakajima Y, Sakai K, Suzuki G, Satoh N, Shinzato C (2016) Unexpectedly complex gradation of coral population structure in the Nansei Islands, Japan. Ecol Evol 6:5491-5505. doi: 10.1002/ece3.2296

\section{Electronic supplementary material}

Online Resource 1 Loci used in this study

Online Resource 2 Pocillopora PSH04 genetic identification

Online Resource 3 Supplementary method

Online Resource 4 Sampled sites in New Caledonia ecoregion and Pocillopora PSH04 cluster distribution

Online Resource 5 Distributions of the pairwise genetic distances between multi-locus genotypes

Online Resource 6 Comparison of the genetic assignment analysis for the four datasets

Online Resource 7 Genetic assignment analysis of the Pocillopora PSH04 colonies

Online Resource 8 Pocillopora PSH04 Secondary Species Hypotheses 
809 Online Resource 9 Pocillopora PSH04 clusters

810 Online Resource 10 Genetic assignment analysis of the Pocillopora PSH04 colonies, for each 811 Secondary Species Hypothesis separately

812 Online Resource 11 Pocillopora SSH04a clusters

813 Online Resource 12 Pocillopora PSH04 population summary statistics at 8 loci

814 Online Resource 13 Genetic differentiation among populations

815 Online Resource 14 Relative migration networks

816 Online Resource 15 Pocillopora PSH04 corallum macromorphology diversity 
Cryptic species and genetic connectivity among populations of the coral Pocillopora damicornis (Scleractinia) in the tropical southwestern Pacific - Marine Biology Original Paper-

Nicolas Oury, Pauline Gélin, Hélène Magalon

Corresponding author: Nicolas Oury, UMR ENTROPIE, Université de La Réunion, Faculté des Sciences et Technologies, 15 bd René Cassin, CS 92003, 97744 St Denis Cedex 09, La Réunion. Email: nicolasoury@ hotmail.fr

Online Resource 1 Loci used in this study, regrouped in panels. Size ranges (in base pairs) are given for this study. \%NA: percentage of missing data; $N a$ : number of alleles

\begin{tabular}{|c|c|c|c|c|c|c|c|}
\hline Panel & Locus name & Repeat motif & Dye & Size (bp) & $\% N A$ & $\mathrm{Na}$ & Reference \\
\hline \multirow{5}{*}{1} & Pd3-004 & $(\mathrm{ATG})_{8}$ & 6-FAM & $178-190$ & $8.0 \%$ & 5 & [4] \\
\hline & Poc40 & $(\mathrm{CAA})_{\mathrm{X}}$ & 6-FAM & $308-341$ & $86.2 \%$ & - & [3] \\
\hline & Pd3-005 & $(\mathrm{TGA})_{9}$ & NED & $206-272$ & $19.4 \%$ & 22 & [4] \\
\hline & PV2 & $(\mathrm{GA})_{20}$ & VIC & $147-181$ & $15.3 \%$ & 6 & [2] \\
\hline & PV7 & $(\mathrm{GT})_{5}(\mathrm{CT})_{2} \mathrm{GT}(\mathrm{CT})_{3}$ & VIC & $242-260$ & $3.2 \%$ & 9 & [2] \\
\hline \multirow{4}{*}{2} & Pd2-001 & $(\mathrm{CA})_{11}$ & VIC & $212-216$ & $6.3 \%$ & 8 & [4] \\
\hline & Pd2-006 & $(\mathrm{CA})_{8}$ & NED & $205-237$ & $8.3 \%$ & 13 & [4] \\
\hline & Pd3-008 & $(\mathrm{CTG})_{7}$ & 6-FAM & 176-197 & $3.9 \%$ & 8 & [4] \\
\hline & Pd3-009 & $(\mathrm{CAA})_{7}(\mathrm{GAG})_{6}$ & 6-FAM & $333-372$ & $33.4 \%$ & - & [4] \\
\hline \multirow{7}{*}{3} & Pd3-EF65 & $(\mathrm{GTT})_{5}(\mathrm{TGC})_{11}$ & PET & $197-242$ & $19.7 \%$ & 15 & [1] \\
\hline & $\mathrm{Pd} 4$ & $(\mathrm{AAAC})_{5}$ & 6-FAM & $144-164$ & $7.5 \%$ & 11 & [5] \\
\hline & Pd11 & $(\mathrm{CA})_{7} \mathrm{~T}(\mathrm{AC})_{13}$ & VIC & $142-172$ & $8.6 \%$ & 13 & [5] \\
\hline & $\operatorname{Pd} 13$ & $(\mathrm{TCTT})_{5}$ & NED & $160-200$ & $7.4 \%$ & 12 & [5] \\
\hline & & & & Total $_{13 \text { loci }}$ & $17.5 \%$ & - & \\
\hline & & & & Total $_{11 \text { loci }}$ & $9.8 \%$ & $11.1 \pm 1.4$ & \\
\hline & & & & Totals loci & $6.7 \%$ & $9.9 \pm 0.9$ & \\
\hline
\end{tabular}

[1] Gorospe KD, Karl SA (2013) Genetic relatedness does not retain spatial pattern across multiple spatial scales: dispersal and colonization in the coral, Pocillopora damicornis. Mol Ecol 22:3721-3736

[2] Magalon H, Samadi S, Richard M, Adjeroud M, Veuille M (2004) Development of coral and zooxanthellaspecific microsatellites in three species of Pocillopora (Cnidaria, Scleractinia) from French Polynesia. Mol Ecol Notes 4:206-208

[3] Pinzón JH, LaJeunesse TC (2011) Species delimitation of common reef corals in the genus Pocillopora using nucleotide sequence phylogenies, population genetics and symbiosis ecology. Mol Ecol 20:311325

[4] Starger CJ, Yeoh SS, Dai CF, Baker AC, Desalle ROB (2008) Ten polymorphic STR loci in the cosmopolitan reef coral, Pocillopora damicornis. Mol Ecol Res 8:619-621

[5] Torda G, Schmidt-Roach S, Peplow LM, Lundgren P, van Oppen MJH (2013) A rapid genetic assay for the identification of the most common Pocillopora damicornis genetic lineages on the great barrier reef. PLoS ONE 8:e58447 
Cryptic species and genetic connectivity among populations of the coral Pocillopora damicornis (Scleractinia) in the tropical southwestern Pacific

- Marine Biology Original Paper-

Nicolas Oury, Pauline Gélin, Hélène Magalon

Corresponding author: Nicolas Oury, UMR ENTROPIE, Université de La Réunion, Faculté des Sciences et Technologies, 15 bd René Cassin, CS 92003 , 97744 St Denis Cedex 09, La Réunion. Email: nicolasoury@ hotmail.fr

Online Resource 2 Pocillopora PSH04 genetic identification. Mean STRUCTURE assignments over the five iterations at $K=12$ for (a) all colonies, Q-sorted, and (b) only colonies with their Open Reading Frame (ORF) haplotype identified $(N=943)$, Q-sorted per haplotype. Primary Species Hypotheses (PSHs; sensu Gélin et al 2017) are indicated above each chart and ORF haplotypes (sensu Gélin et al. 2017) are indicated below chart (b). Horizontal dashed lines represent a PSH04 assignment probability (fuchsia bars) of 0.75 and vertical dashed lines in (a) delimit the colonies identified as PSH04 in this study (i.e. with a PSH04 assignment probability $\geq 0.75$; $N=462)$.

(a)

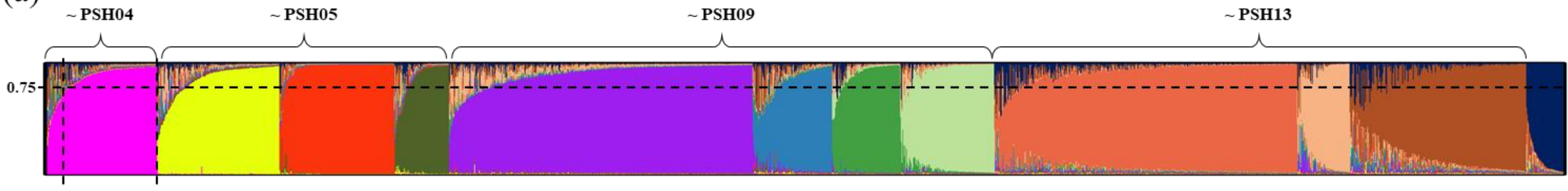

(b)

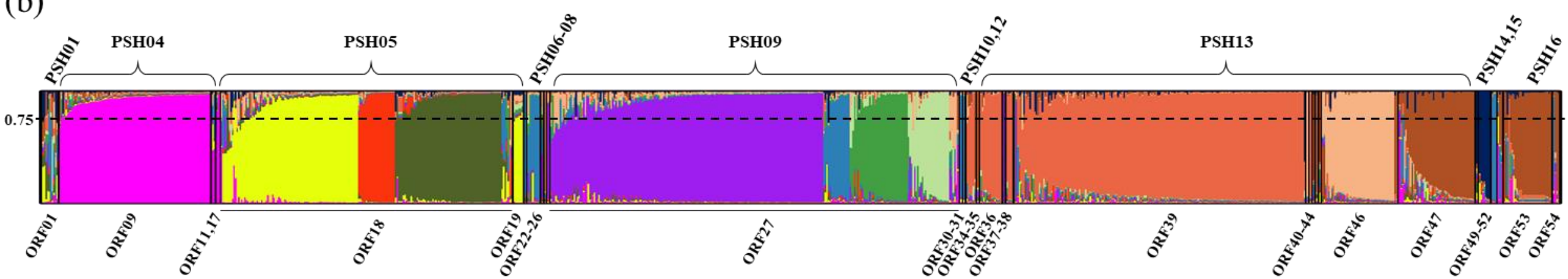

\section{Reference}

Gélin P, Postaire B, Fauvelot C, Magalon H (2017a) Reevaluating species number, distribution and endemism of the coral genus Pocillopora Lamarck, 1816 using species delimitation methods and microsatellites. Mol Phylogenet Evol 109:430-446. doi: 10.1016/j.ympev.2017.01.018 
Cryptic species and genetic connectivity among populations of the coral Pocillopora damicornis (Scleractinia) in the tropical southwestern Pacific - Marine Biology Original Paper-

Nicolas Oury, Pauline Gélin, Hélène Magalon

Corresponding author: Nicolas Oury, UMR ENTROPIE, Université de La Réunion, Faculté des Sciences et Technologies, 15 bd René Cassin, CS 92003, 97744 St Denis Cedex 09, La Réunion. Email: nicolasoury @ hotmail.fr

Online Resource 3 Supplementary method for the genetic partitioning exploration

To infer the genetic partitioning within PSH04, a Bayesian analysis was performed with STRUCTURE 2.3.4 (Pritchard et al. 2000). The admixture model with default settings for inferring alpha was used, assuming correlated allele frequencies. Five iterations of $10^{6} \mathrm{MCMC}$ generations after an initial burn-in of $10^{5}$ generations were run for each $K$, varying from $K=1$ to $K=10$. The five iterations of each $K$ were then combined by averaging the assignment probabilities of each genetic group using STRUCTURE HARVESTER 0.6.94 (Earl 2012). Results were combined with CLUMPP 1.1.2 (Jakobsson and Rosenberg 2007) and visualised with DISTRUCT 1.1 (Rosenberg 2004). The web program CLUMPAK (Kopelman et al. 2015) was also used. In addition to direct examination of graphical results from STRUCTURE, the mean likelihood over several iterations of the same $K[\operatorname{Pr}(X \mid K)$; Pritchard et al. 2000) and the Evanno's $\Delta K$ (Evanno et al. 2005) were estimated with STRUCTURE HARVESTER to help defining $K$. However, as STRUCTURE analyses are based on strong hypotheses on populations (Hardy-Weinberg equilibrium and no linkage disequilibrium), a discriminant analysis of principal components (DAPC; Jombart et al. 2010) was also performed with the package 'adegenet' (Jombart 2008) from the software R 3.1.1 (R Core Team 2016). Results from DAPC were represented like STRUCTURE plots to ease the comparison of both methods. Then, for each value of $K$, a Minimum Spanning Tree (MST) based on the shared allele distance between colonies was built with EDENETWORKS 2.18 (Kivelä et al. 2015). The nodes were coloured according to the genetic groups previously assigned in STRUCTURE with an average probability over the five iterations of at least 0.75 (i.e. the minimum probability for which assignments in all datasets are strictly identical). Moreover, for each group, the allele frequencies of each locus were calculated and compared between groups. $F_{S T}$ (Weir and Cockerham 1984) between each pair of groups were estimated for each locus and for all loci using GENEPOP 4.7.0 (Raymond and Rousset 1995; Rousset 2008). We then defined the most likely number of genetically homogeneous groups $(K)$ within the colonies as the highest $K$ for which all previous methods (STRUCTURE, DAPC, MST, allelic frequencies and $F_{S T}$ ) were congruent for each dataset. This level of differentiation should correspond to the Secondary Species Hypothesis (SSH) level.

In a hierarchical approach, and as a first level of structuration can hide a second one (see Gélin et al. 2018a), these analyses were repeated on each SSH separately. Once this second level of structuration has been tested, we defined the final number of genetic homogeneous groups (i.e. the clusters).

\section{References}

Earl DA (2012) STRUCTURE HARVESTER: a website and program for visualizing STRUCTURE output and implementing the Evanno method. Conserv Genet Resour 4:359-361. doi: 10.1007/s12686-011-9548-7

Evanno G, Regnaut S, Goudet J (2005) Detecting the number of clusters of individuals using the software STRUCTURE: a simulation study. Mol Ecol 14:2611-2620. doi: 10.1111/j.1365-294X.2005.02553.x 
Gélin P, Fauvelot C, Bigot L, Baly J, Magalon H (2018) From population connectivity to the art of striping Russian dolls: the lessons from Pocillopora corals. Ecol Evol 8:1411-1426. doi: 10.1002/ece3.3747

Jakobsson M, Rosenberg NA (2007) CLUMPP: a cluster matching and permutation program for dealing with label switching and multimodality in analysis of population structure. Bioinformatics 23:1801-1806. doi: 10.1093/bioinformatics/btm233

Jombart T (2008) adegenet: a R package for the multivariate analysis of genetic markers. Bioinformatics 24:1403-1405.

Jombart T, Devillard S, Balloux F (2010) Discriminant analysis of principal components: a new method for the analysis of genetically structured populations. BMC Genet 11:94. doi: 10.1186/1471-2156-11-94

Kivelä M, Arnaud-Haond S, Saramäki J (2015) EDENetworks: a user-friendly software to build and analyse networks in biogeography, ecology and population genetics. Mol Ecol Resour 15:117-122. doi: 10.1111/1755-0998.12290

Kopelman NM, Mayzel J, Jakobsson M, Rosenberg NA, Mayrose I (2015) CLUMPAK: a program for identifying clustering modes and packaging population structure inferences across K. Mol Ecol Resour 15:1179-1191. doi: 10.1111/1755-0998.12387

Pritchard JK, Stephens M, Donnelly P (2000) Inference of population structure using multilocus genotype data. Genetics 155:945-959.

R Core Team (2016) R: a language and environment for statistical computing. R Foundation for Statistical Computing, Vienna, Austria. URL: https://www.R-project.org/

Raymond M, Rousset F (1995) GENEPOP: Population genetics software for exact tests and ecumenism. J Hered 86:248249. doi: 10.1111/j.1558-5646.1995.tb04456.x

Rosenberg NA (2004) DISTRUCT: a program for the graphical display of population structure. Mol Ecol Notes 4:137-138. doi: 10.1046/j.1471-8286.2003.00566.x

Rousset F (2008) Genepop'007: a complete re-implementation of the genepop software for Windows and Linux. Mol Ecol Resour 8:103-106. doi: 10.1111/j.1471-8286.2007.01931.x

Weir BS, Cockerham CC (1984) Estimating F-statistics for the analysis of population structure. Evolution 38:1358-1370. doi: 10.1111/j.1558-5646.1984.tb05657.x 
Cryptic species and genetic connectivity among populations of the coral Pocillopora damicornis (Scleractinia) in the tropical southwestern Pacific - Marine Biology Original Paper-

Nicolas Oury, Pauline Gélin, Hélène Magalon

Corresponding author: Nicolas Oury, UMR ENTROPIE, Université de La Réunion, Faculté des Sciences et Technologies, 15 bd René Cassin, CS 92003, 97744 St Denis Cedex 09, La Réunion. Email: nicolasoury @ hotmail.fr

Online Resource 4 Sampled sites in New Caledonia ecoregion and Pocillopora PSH04 cluster distribution. $N$ : number of colonies

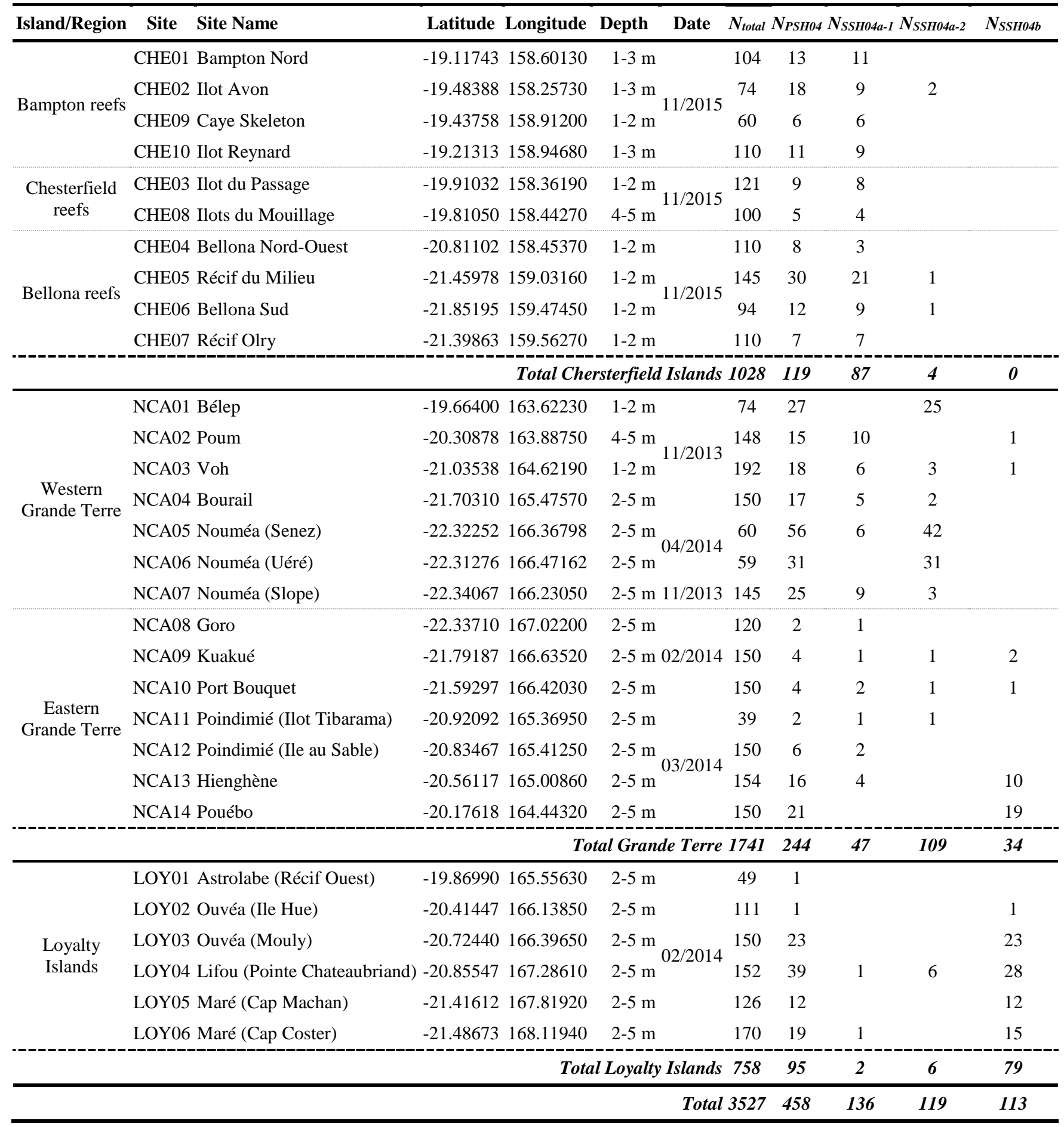


Cryptic species and genetic connectivity among populations of the coral Pocillopora damicornis (Scleractinia) in the tropical southwestern Pacific - Marine Biology Original Paper-

Nicolas Oury, Pauline Gélin, Hélène Magalon

Corresponding author: Nicolas Oury, UMR ENTROPIE, Université de La Réunion, Faculté des Sciences et Technologies, 15 bd René Cassin, CS 92003, 97744 St Denis Cedex 09, La Réunion. Email: nicolasoury @ hotmail.fr

Online Resource 5 Distributions of the pairwise genetic distances between multi-locus genotypes (MLGs) under the Infinite Allele Model (IAM) and the Stewise Mutational Model (SMM), at (a) 11 and (b) 8 loci.

(a) 11 loci $(89,253$ comparisons $)$

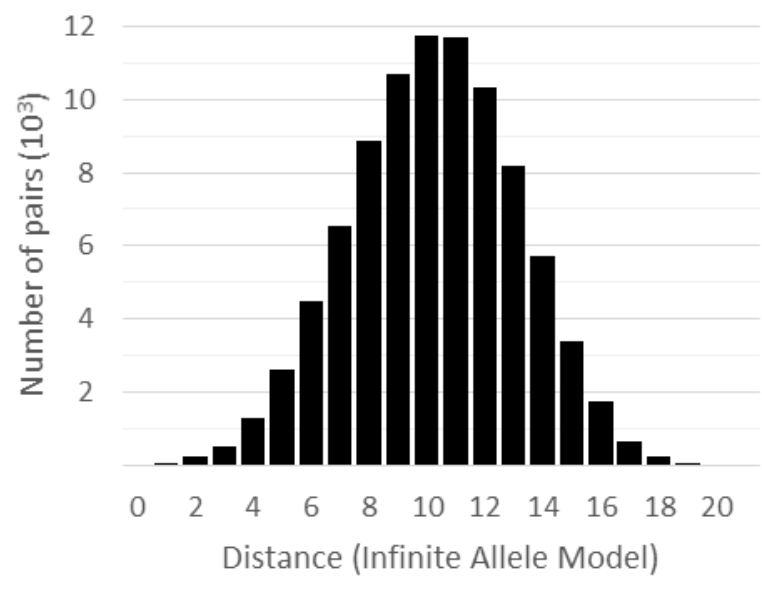

(b) 8 loci (77,815 comparisons)

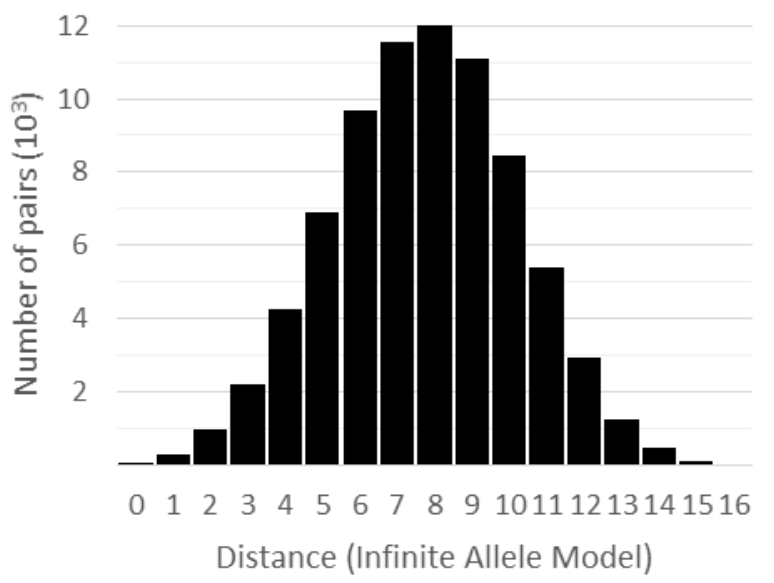

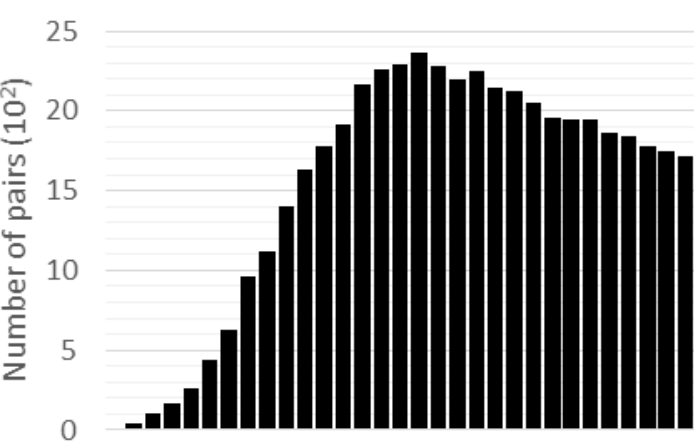

$0 \quad 246 \quad 81012141618202224262830$ Distance (Stepwise Mutational Model)

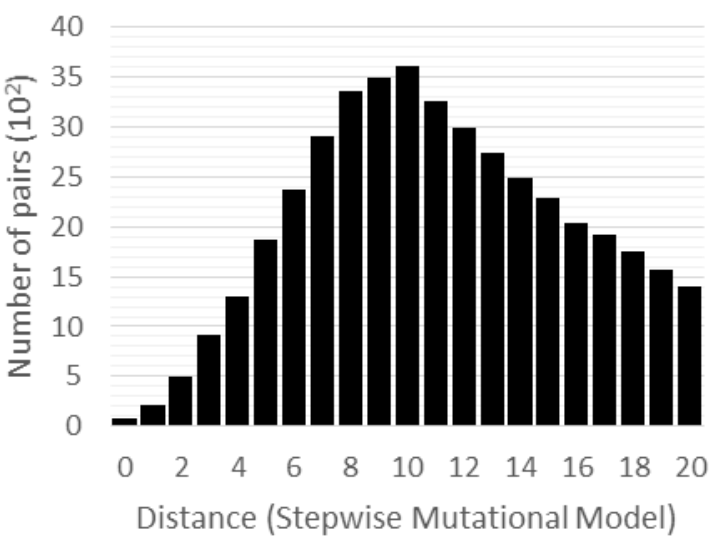


Cryptic species and genetic connectivity among populations of the coral Pocillopora damicornis (Scleractinia) in the tropical southwestern Pacific - Marine Biology Original Paper-

Nicolas Oury, Pauline Gélin, Hélène Magalon

Corresponding author: Nicolas Oury, UMR ENTROPIE, Université de La Réunion, Faculté des Sciences et Technologies, 15 bd René Cassin, CS 92003 , 97744 St Denis Cedex 09, La Réunion. Email: nicolasoury@ hotmail.fr

Online Resource 6 Comparison of the genetic assignment analysis [STRUCTURE (S.) and DAPC (D.) plots from $K=2$ to $K=5$ ] for the four Pocillopora PSH04 datasets: (a) Entire_11, (b) Truncated_11, (c) Entire_8 and (d) Truncated_8.
(a)
Chesterfield Islands
Grande Terre
Loyalty Islands (b)
Chesterfield Islands
Grande Terre
Loyalty Islands

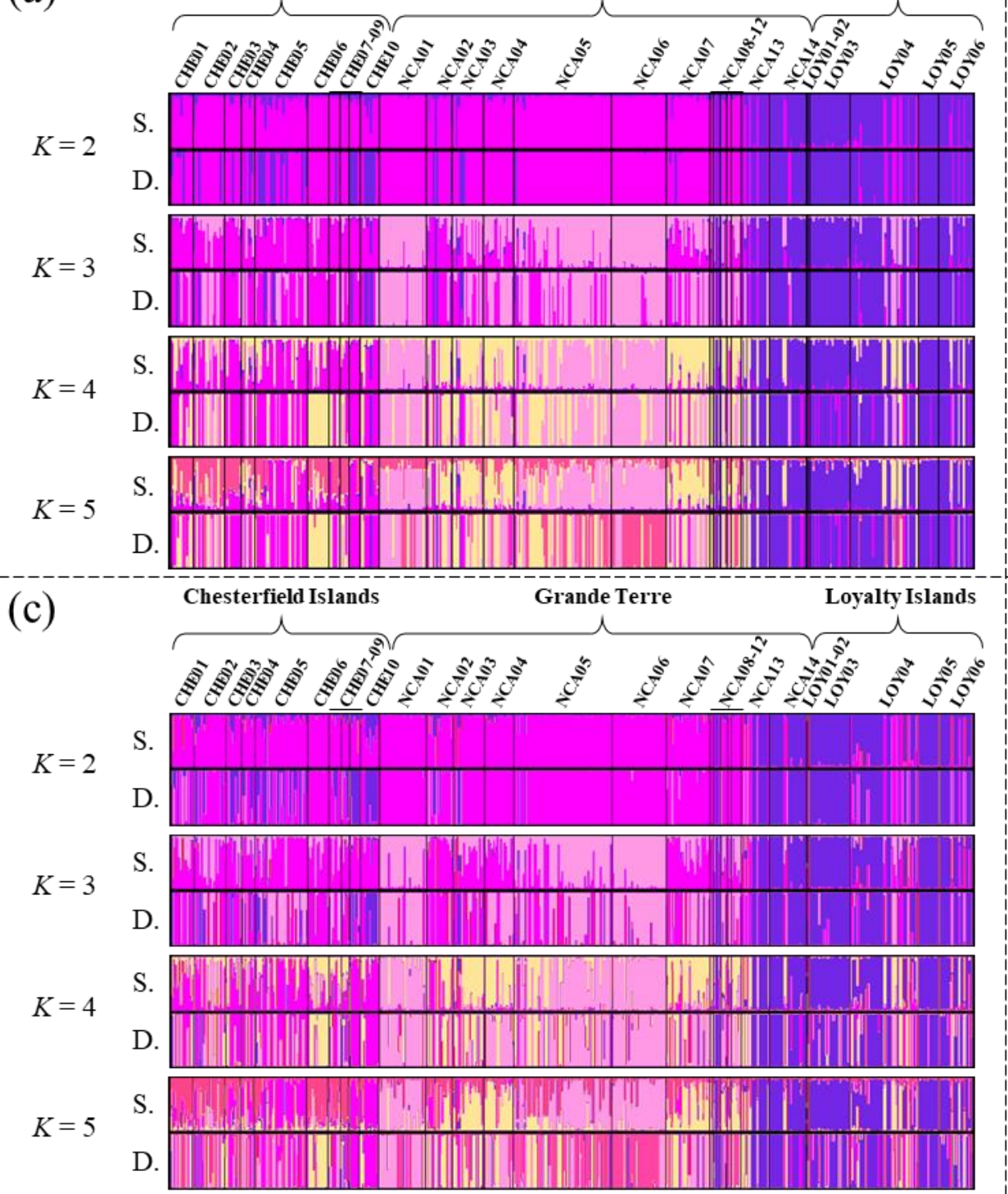
$K=2$

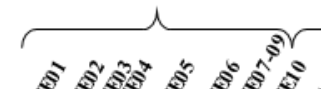
$\overbrace{}^{2}$
$\underbrace{2 i^{2}}$
S.
D.
$K=3$
S.

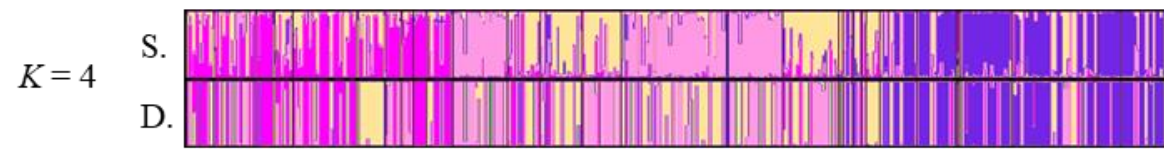
$K=5$
S.
(d)
D.

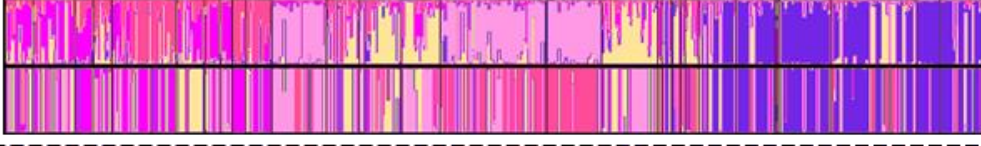
Chesterfield Islands
Grande Terre
Loyalty Islands

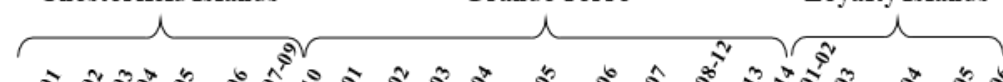 $K=2$
$\mathrm{S}$.

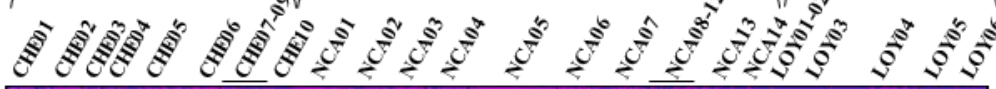
D.
$K=3$
S.
$K=4$
S.

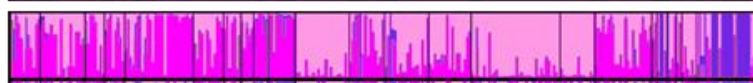

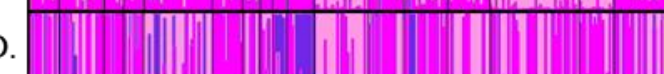
$K=5$

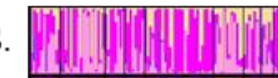
(I)

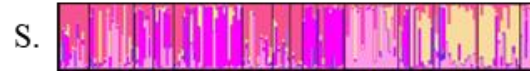

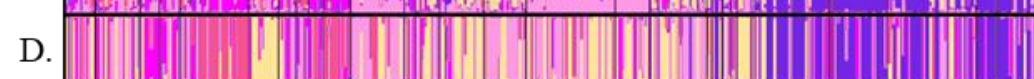


Cryptic species and genetic connectivity among populations of the coral Pocillopora damicornis (Scleractinia) in the tropical southwestern Pacific - Marine Biology Original Paper-

Nicolas Oury, Pauline Gélin, Hélène Magalon

Corresponding author: Nicolas Oury, UMR ENTROPIE, Université de La Réunion, Faculté des Sciences et Technologies, 15 bd René Cassin, CS 92003, 97744 St Denis Cedex 09, La Réunion. Email: nicolasoury @ hotmail.fr

Online Resource 7 Genetic assignment analysis of the Pocillopora PSH04 colonies (Entire_11 dataset). (a) mean likelihood over the five iterations of the same $K$, (b) Evanno's $\Delta K$ distribution, (c) BIC distribution and (d) plots from $K=2$ to $K=10$ for STRUCTURE (S.) and DAPC (D.)

(a)

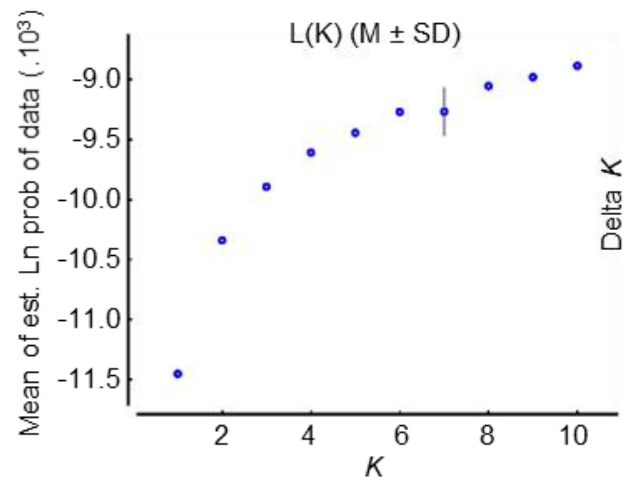

(b)

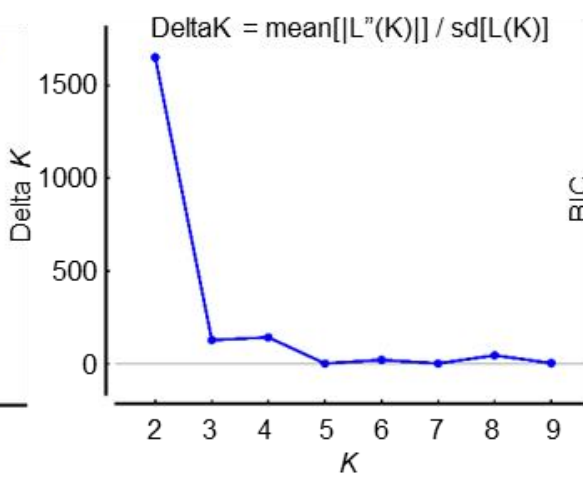

(c)

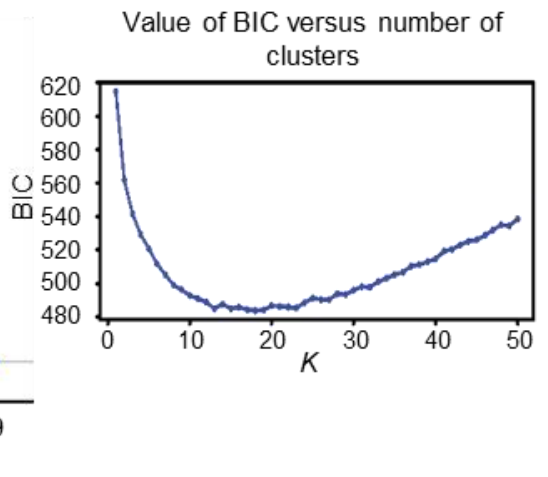

(d)

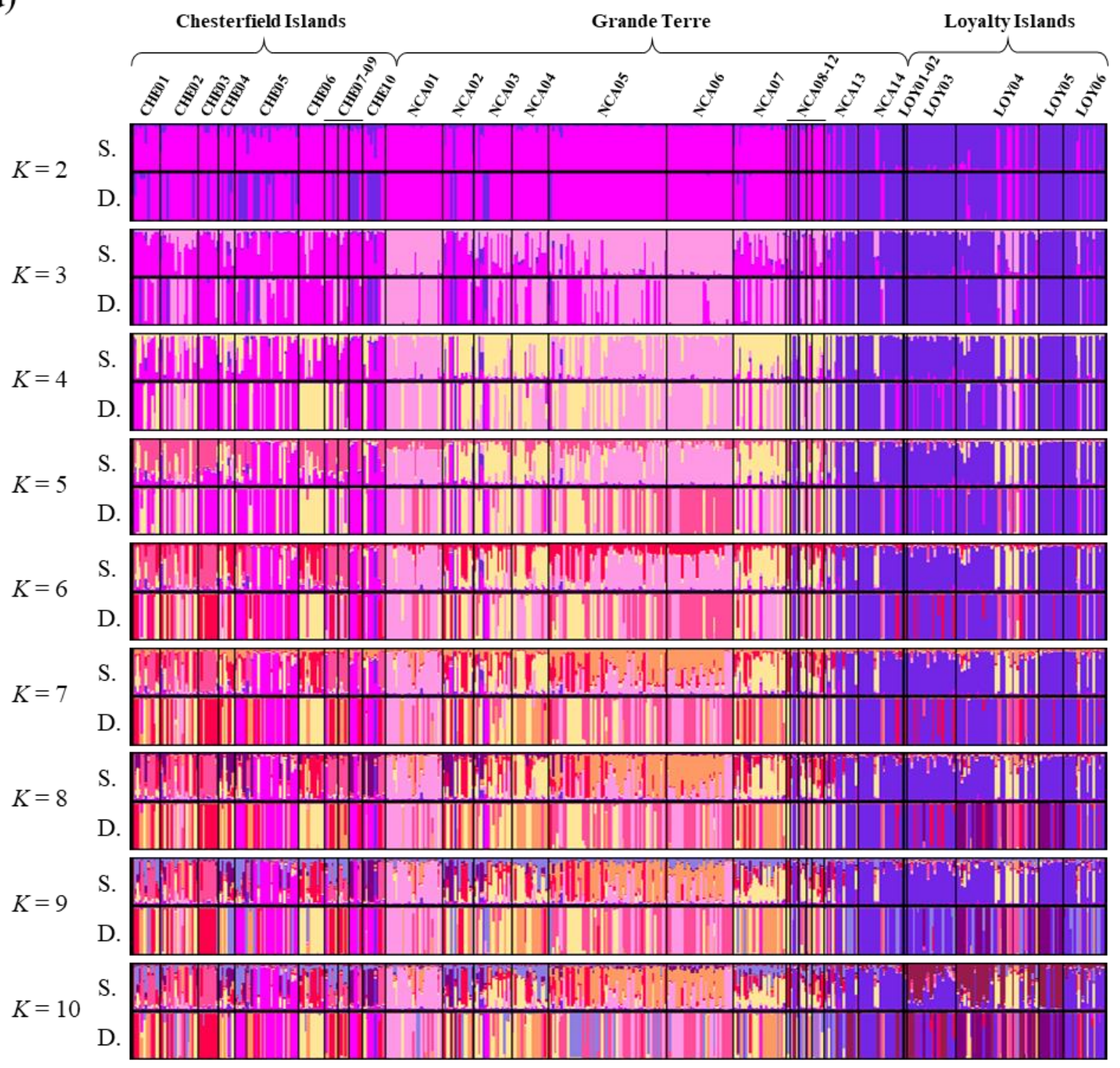


Cryptic species and genetic connectivity among populations of the coral Pocillopora damicornis (Scleractinia) in the tropical southwestern Pacific - Marine Biology Original Paper-

Nicolas Oury, Pauline Gélin, Hélène Magalon

Corresponding author: Nicolas Oury, UMR ENTROPIE, Université de La Réunion, Faculté des Sciences et Technologies, 15 bd René Cassin, CS 92003, 97744 St Denis Cedex 09, La Réunion. Email: nicolasoury @ hotmail.fr

Online Resource 8 Pocillopora PSH04 Secondary Species Hypotheses (SSHs; Entire_11 dataset). (a) STRUCTURE plot at $K=2$, (b) DAPC assignments, (c) Minimum Spanning Tree, (d) allelic frequencies for each locus and each SSH and (e) Weir and Cockerham (1984) $F_{S T}$ estimated per locus. Colonies are coloured according to the genetic groups identified by STRUCTURE (individual assignment probability $\geq 0.75$ ). Colonies with an assignment probability inferior to 0.75 for each group were coloured in grey

(a)

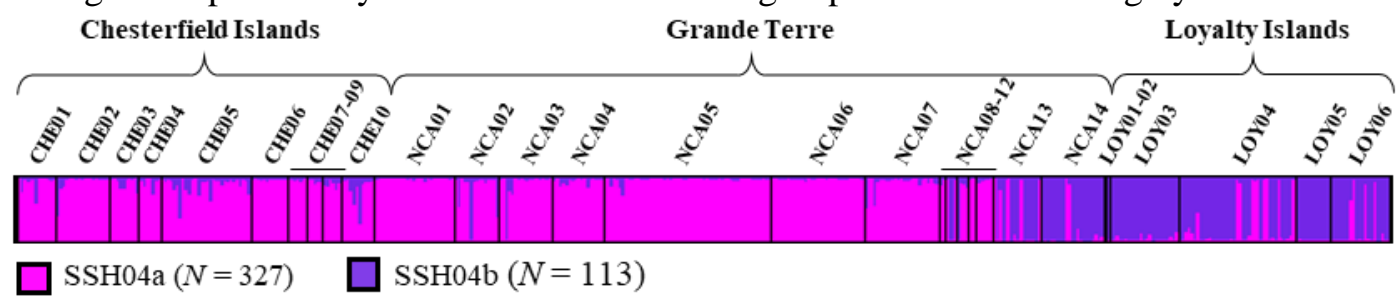

(b)

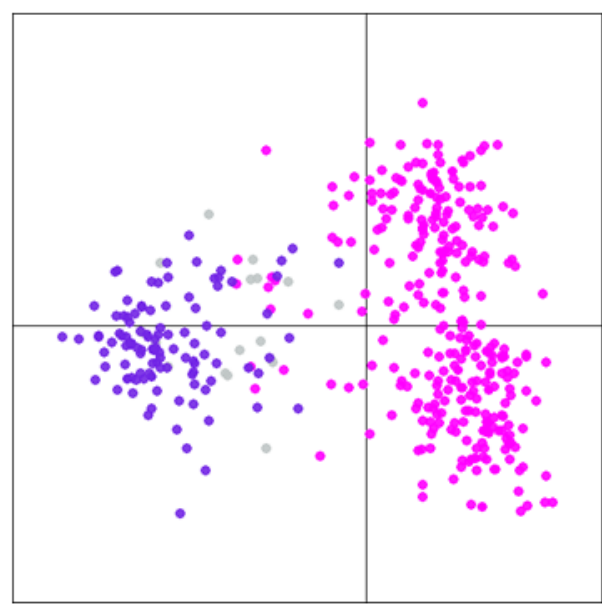

(c)

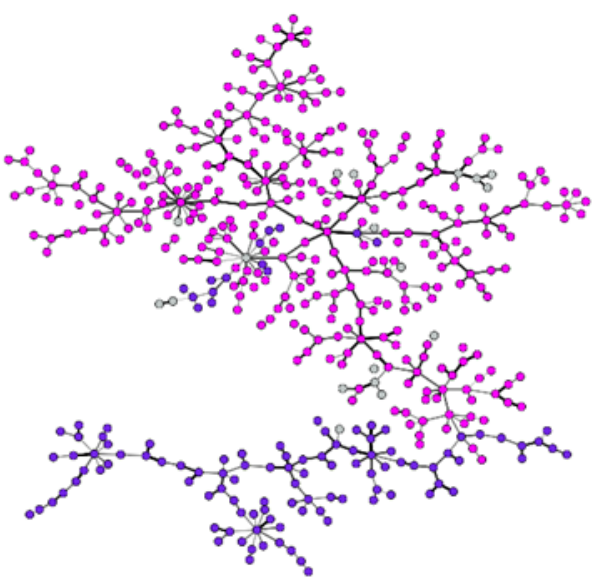

(d)

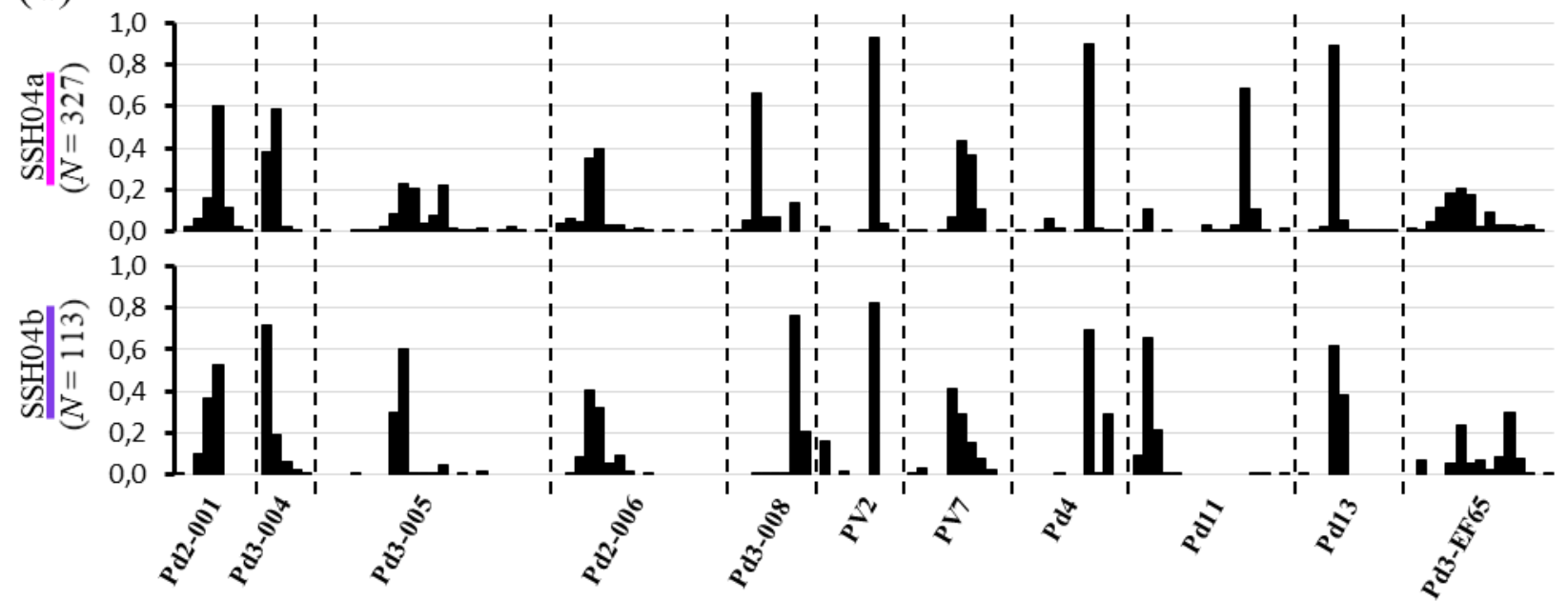

(e)

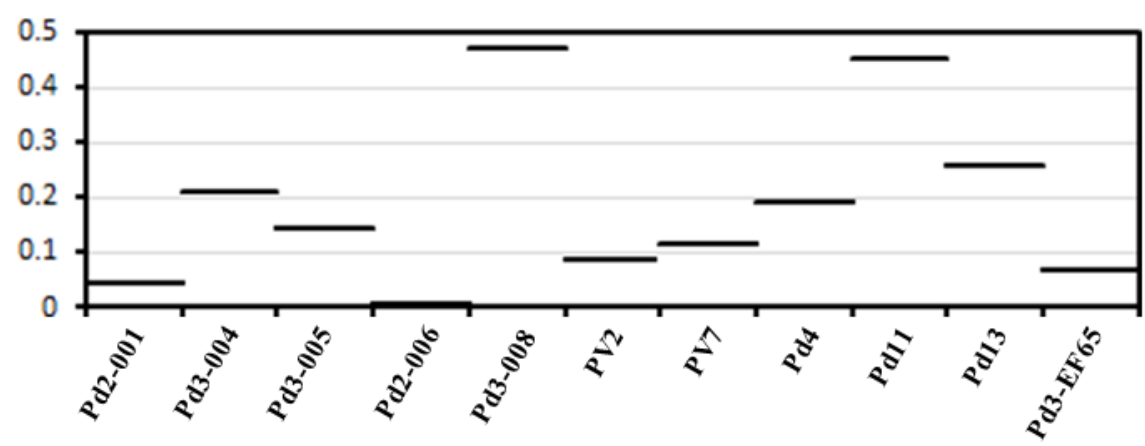


Cryptic species and genetic connectivity among populations of the coral Pocillopora damicornis (Scleractinia) in the tropical southwestern Pacific - Marine Biology Original Paper-

Nicolas Oury, Pauline Gélin, Hélène Magalon

Corresponding author: Nicolas Oury, UMR ENTROPIE, Université de La Réunion, Faculté des Sciences et Technologies, 15 bd René Cassin, CS 92003, 97744 St Denis Cedex 09, La Réunion. Email: nicolasoury @ hotmail.fr

Online Resource 9 Pocillopora PSH04 clusters (Entire_11 dataset). (a) STRUCTURE plot at $K=3$, (b) DAPC assignments, (c) Minimum Spanning Tree, (d) allelic frequencies for each locus and each cluster and (e) Weir and Cockerham (1984) $F_{S T}$ estimated per locus for each pair of clusters. Colonies are coloured according to the clusters identified by STRUCTURE (individual assignment probability $\geq 0.75$ ). Colonies with an assignment probability inferior to 0.75 for each cluster were coloured in grey

(a)

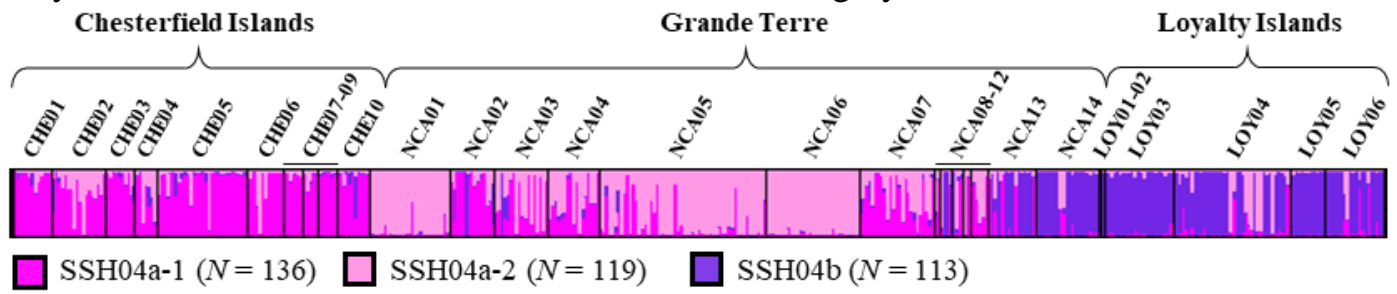

(b)

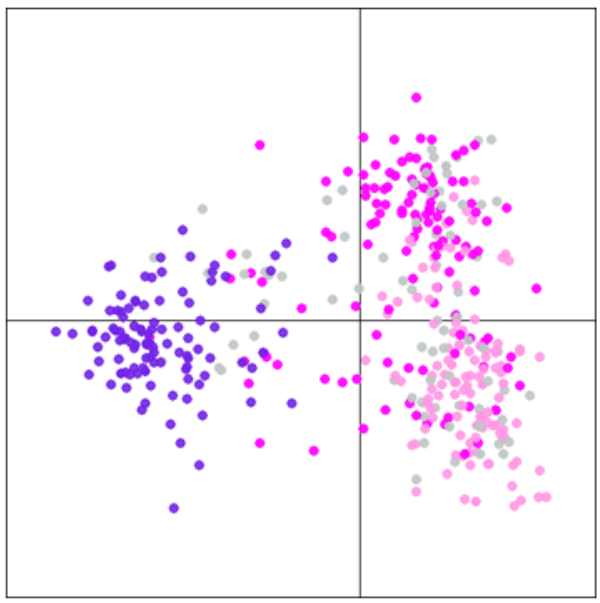

(c)

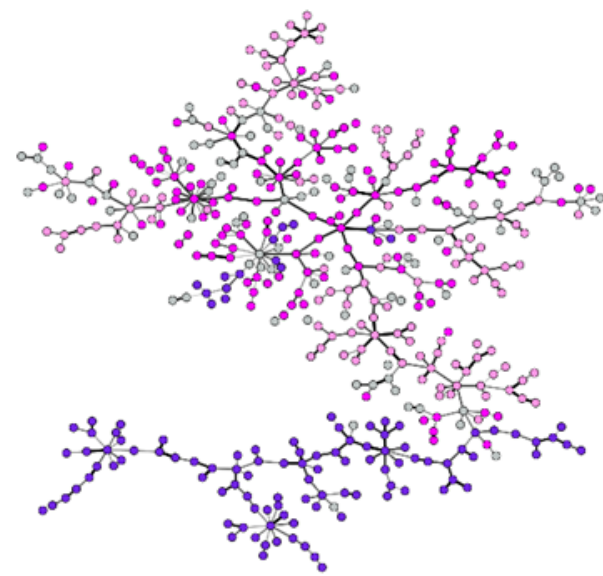

(d)
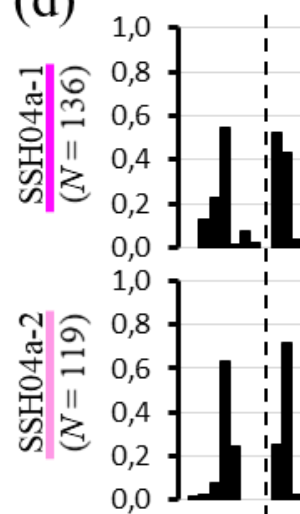

1,0

譤

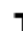

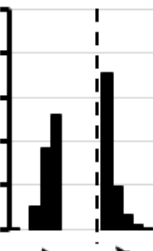

$2^{2}$

(e)

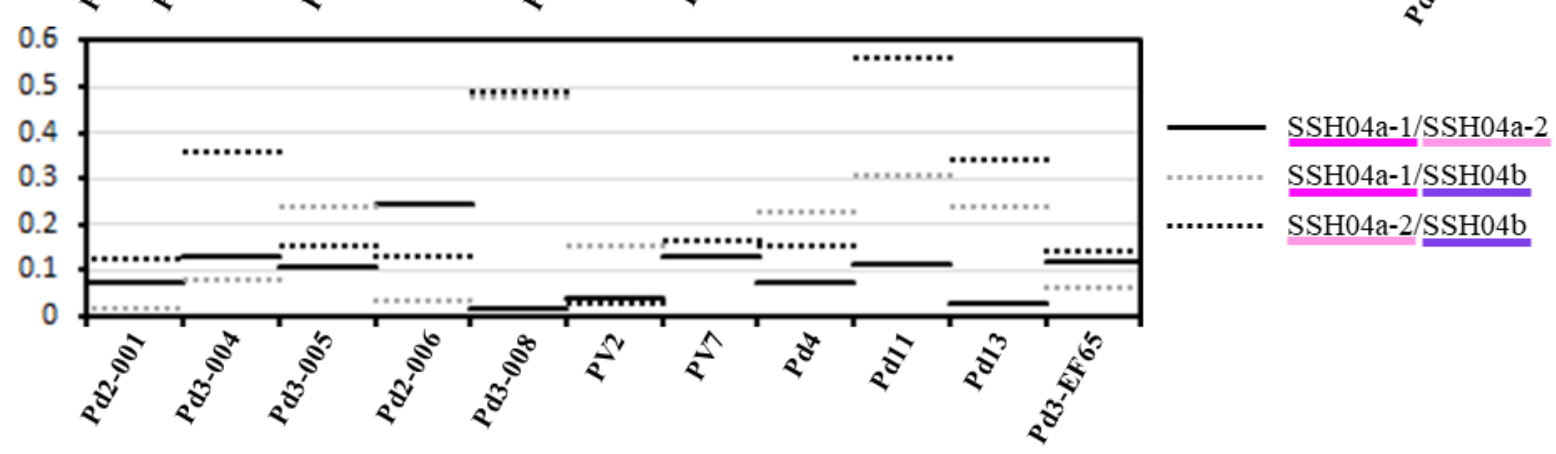


Cryptic species and genetic connectivity among populations of the coral Pocillopora damicornis (Scleractinia) in the tropical southwestern Pacific - Marine Biology Original Paper-

Nicolas Oury, Pauline Gélin, Hélène Magalon

Corresponding author: Nicolas Oury, UMR ENTROPIE, Université de La Réunion, Faculté des Sciences et Technologies, 15 bd René Cassin, CS 92003, 97744 St Denis Cedex 09, La Réunion. Email: nicolasoury@ hotmail.fr

Online Resource 10 Genetic assignment analysis of the Pocillopora PSH04 colonies, for each Secondary Species Hypothesis (SSH) separately (Entire_11 dataset). (a) STRUCTURE (S.) and DAPC (D.) plots at $K=2$ for all colonies and (b) plots from $K=1$ to $K=5$ for each SSH separately

(a)

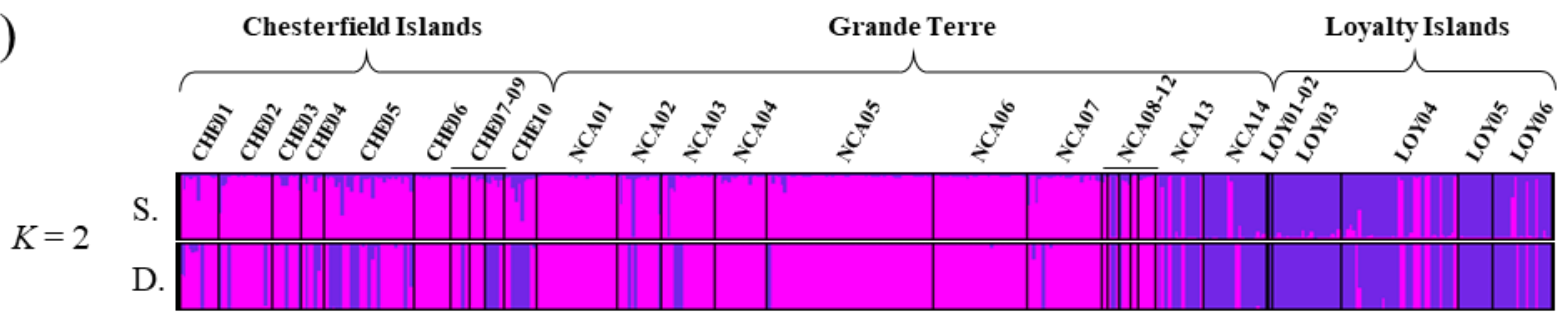

(b) $\square \operatorname{ssH04a}(N=327)$
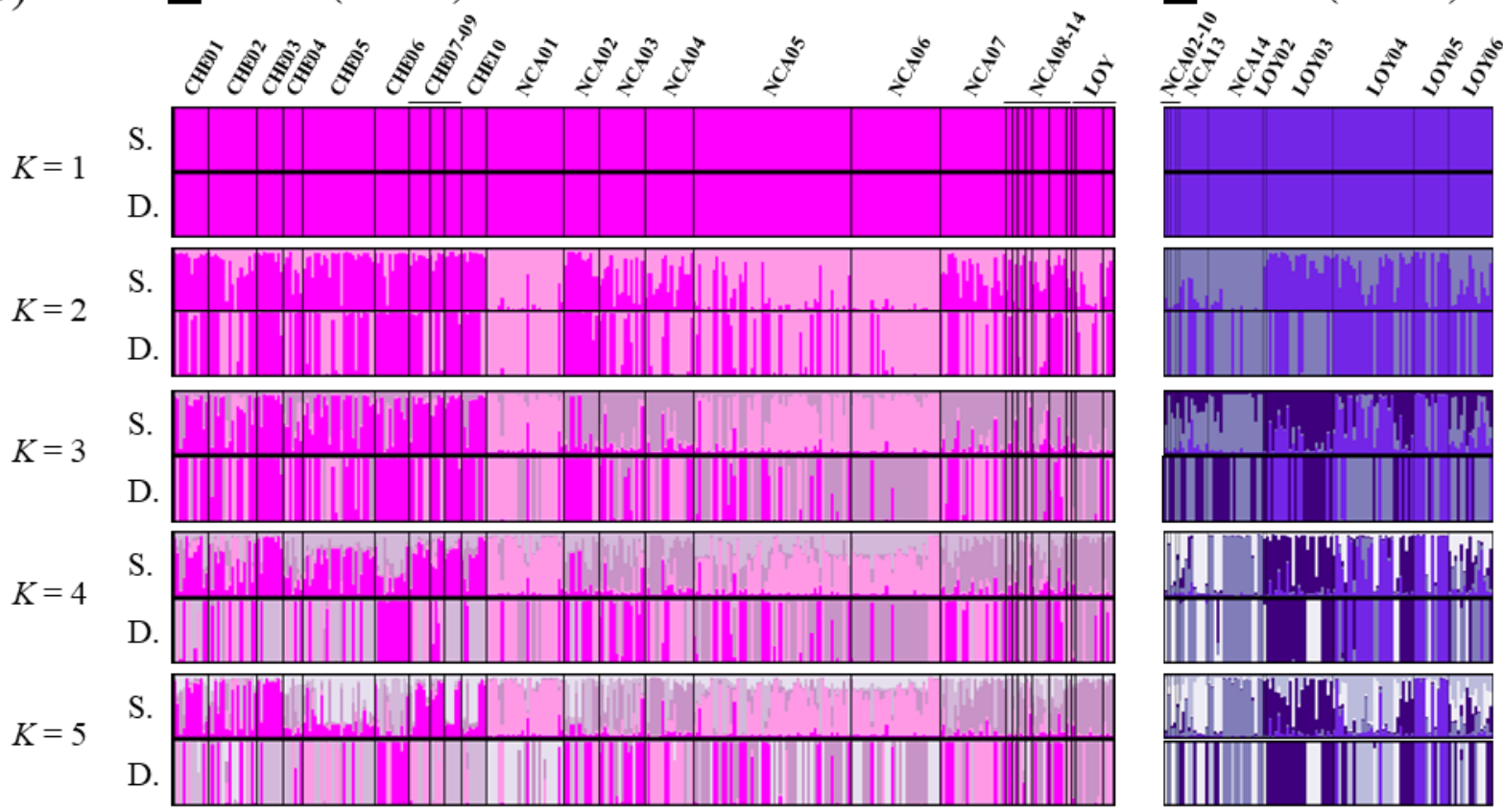

$\mathrm{SSH} 04 \mathrm{~b}(N=113)$

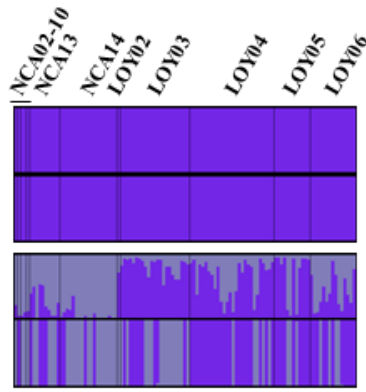

$K=5$

S.

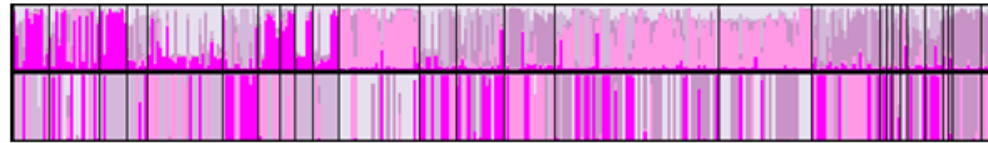


Cryptic species and genetic connectivity among populations of the coral Pocillopora damicornis (Scleractinia) in the tropical southwestern Pacific - Marine Biology Original Paper-

Nicolas Oury, Pauline Gélin, Hélène Magalon

Corresponding author: Nicolas Oury, UMR ENTROPIE, Université de La Réunion, Faculté des Sciences et Technologies, 15 bd René Cassin, CS 92003, 97744 St Denis Cedex 09, La Réunion. Email: nicolasoury @ hotmail.fr

Online Resource 11 Pocillopora SSH04a clusters (Entire_11 dataset). (a) STRUCTURE plot at $K=2$, (b) DAPC assignments, (c) Minimum Spanning Tree, (d) allelic frequencies for each locus and each cluster and (e) Weir and Cockerham (1984) $F_{S T}$ estimated per locus. Colonies are coloured according to the clusters identified by STRUCTURE (individual assignment probability $\geq 0.75$ ). Colonies with an assignment probability inferior to 0.75 for each cluster were coloured in grey

(a)

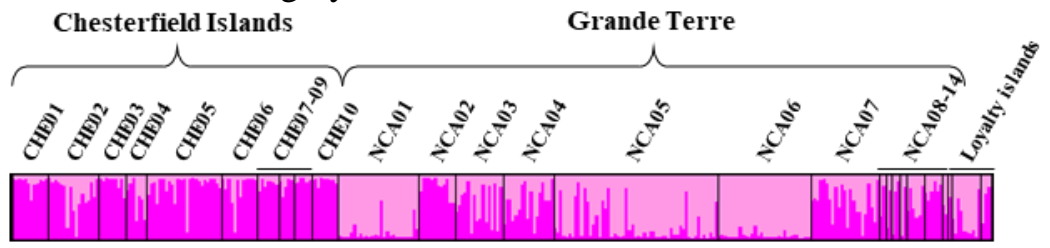

$\operatorname{sSH04a-1}(N=136) \quad \square \operatorname{SSH04a-2}(N=119)$

(b)

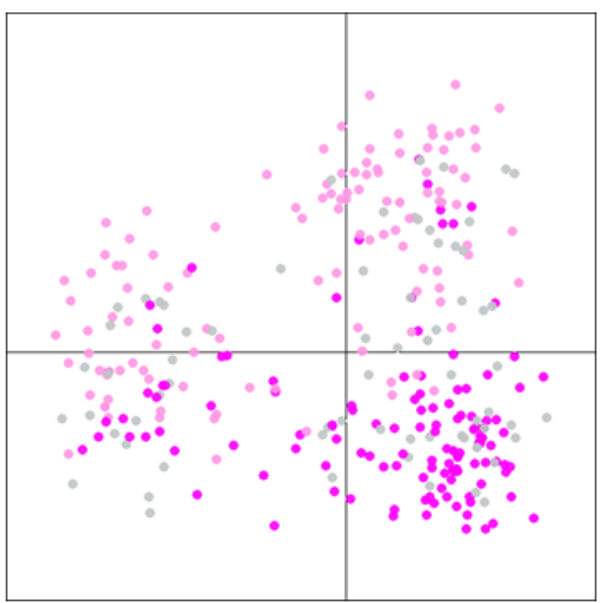

(c)

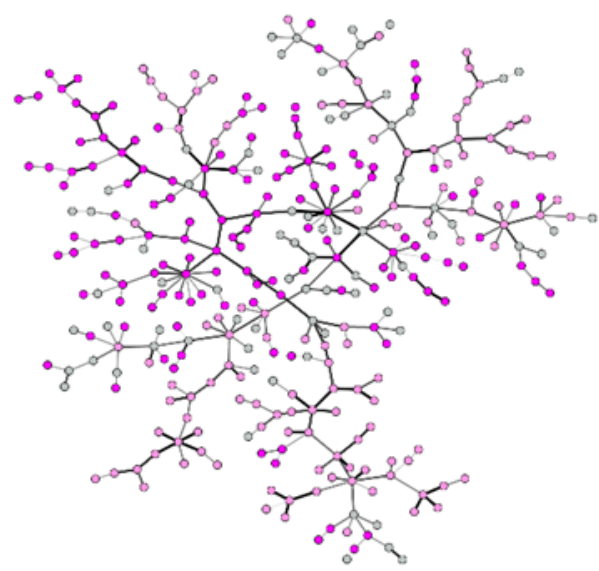

(d)

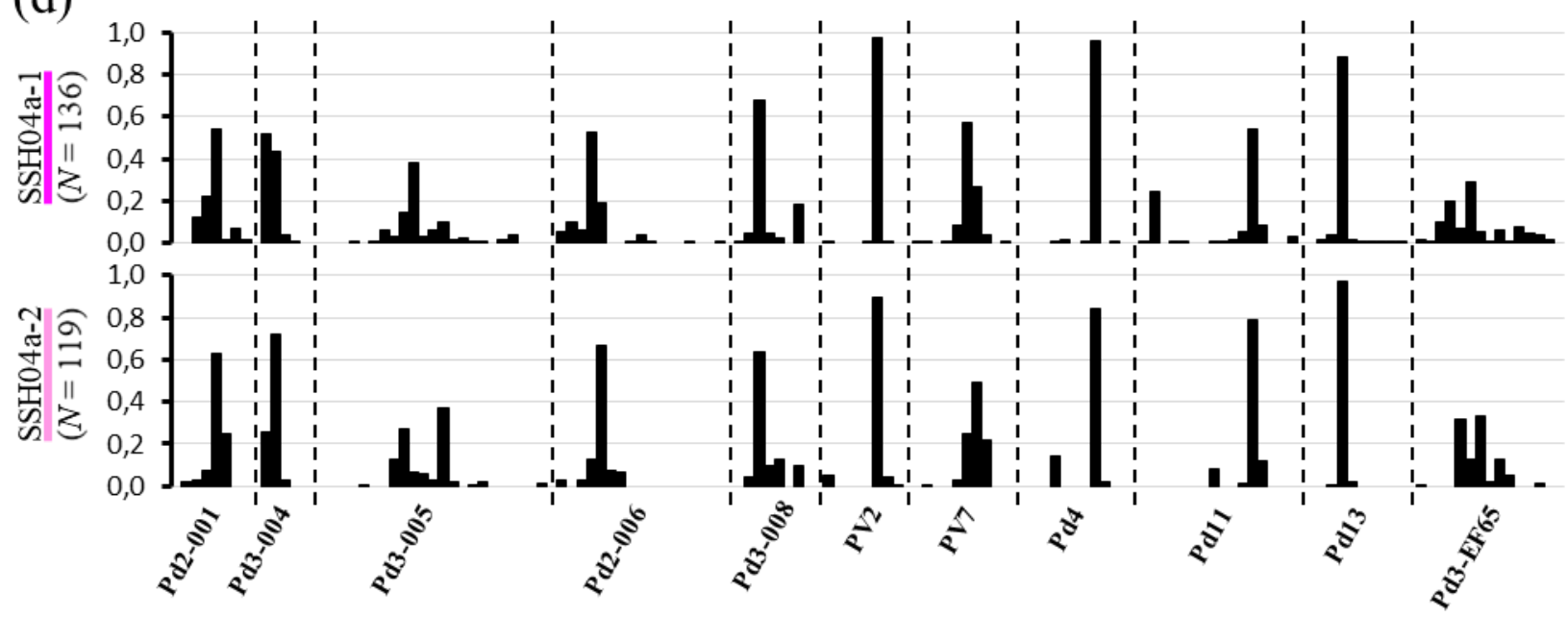

(e)

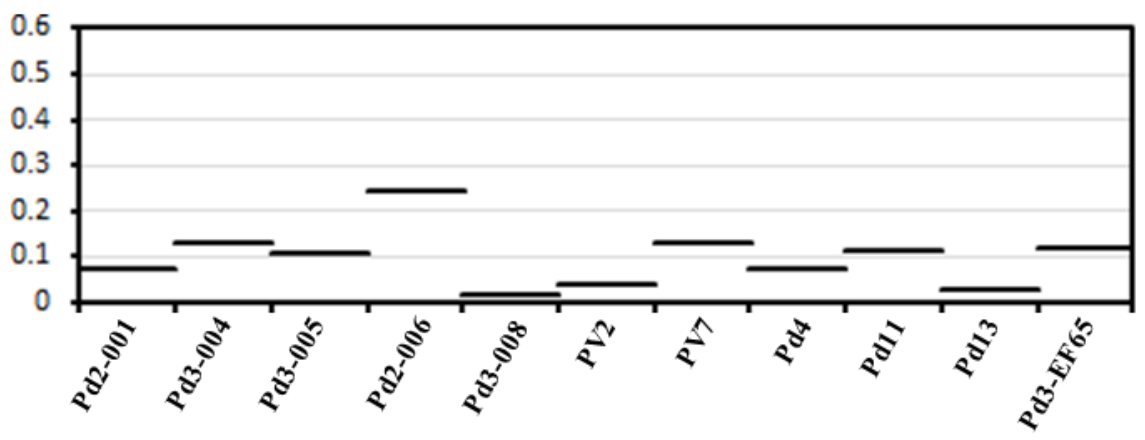


Cryptic species and genetic connectivity among populations of the coral Pocillopora damicornis (Scleractinia) in the tropical southwestern Pacific

- Marine Biology Original Paper-

Nicolas Oury, Pauline Gélin, Hélène Magalon

Corresponding author: Nicolas Oury, UMR ENTROPIE, Université de La Réunion, Faculté des Sciences et Technologies, 15 bd René Cassin, CS 92003 , 97744 St Denis Cedex 09, La Réunion. Email: nicolasoury@ hotmail.fr

Online Resource 12 Pocillopora PSH04 population summary statistics at 8 loci. Only populations with at least 10 colonies were considered. Sites are detailed in Online Resource 4. $N$ : number of colonies; $N_{M L G}$ : number of multi-locus genotypes (MLGs) for both treatments of missing data; $R$ : clonal richness (Dorken and Eckert 2001); \%NA $A_{p o p}$ : percentage of missing data; $P$ : proportion of polymorphic loci; $N a_{p o p}$ and $N p_{p o p}$ : mean numbers ( \pm SE) of alleles and population-private alleles; $H o_{p o p}$ and $H e_{p o p}$ : mean $( \pm \mathrm{SE})$ observed and expected heterozygosities and $F_{I S p o p}$ : mean $( \pm \mathrm{SE})$ inbreeding coefficient [Wright 1931 ; ${ }^{\mathrm{NS}}$ : non-significant $(P>0.05) ; * *$ : $0.001<P<0.01]$

\begin{tabular}{|c|c|c|c|c|c|c|c|c|c|c|c|c|c|}
\hline \multirow{2}{*}{ Population } & \multirow{2}{*}{$N$} & \multirow{2}{*}{$N_{M L G}$} & \multirow{2}{*}{$\boldsymbol{R}$} & \multirow{2}{*}{$\% N A_{p o p}$} & \multirow{2}{*}{$P$} & \multirow{2}{*}{$N a_{p o p}$} & \multirow{2}{*}{$N p_{p o p}$} & \multicolumn{3}{|c|}{ Entire_8 } & \multicolumn{3}{|c|}{ Truncated_8 } \\
\hline & & & & & & & & $H o_{p o p}$ & $H e_{p o p}$ & $F_{I S p o p}$ & $H o_{p o p}$ & $H e_{p o p}$ & $F_{I S ~ p o p}$ \\
\hline \multicolumn{14}{|l|}{ SSH04a-1 } \\
\hline CHE01 & 11 & $10-11$ & $0.90-1.00$ & $10.2 \%$ & $100 \%$ & $2.8 \pm 0.4$ & $0.0 \pm 0.0$ & $0.24 \pm 0.07$ & $0.51 \pm 0.08$ & $0.42 \pm 0.16^{*}$ & $0.25 \pm 0.06$ & $0.52 \pm 0.08$ & $0.41 \pm 0.15^{*}$ \\
\hline CHE05 & 21 & $20-21$ & $0.95-1.00$ & $6.5 \%$ & $100 \%$ & $4.0 \pm 0.6$ & $0.1 \pm 0.1$ & $0.39 \pm 0.08$ & $0.47 \pm 0.10$ & $0.12 \pm 0.05^{\mathrm{NS}}$ & $0.39 \pm 0.08$ & $0.48 \pm 0.10$ & $0.14 \pm 0.06^{*}$ \\
\hline NCA02 & 10 & 9 & 0.89 & $5.0 \%$ & $75 \%$ & $2.5 \pm 0.4$ & $0.1 \pm 0.1$ & $0.46 \pm 0.07$ & $0.49 \pm 0.06$ & $0.05 \pm 0.13^{\mathrm{NS}}$ & $0.43 \pm 0.07$ & $0.49 \pm 0.06$ & $0.08 \pm 0.12^{\mathrm{NS}}$ \\
\hline Total & 136 & $128-132$ & $0.94-0.97$ & $6.3 \%$ & $100 \%$ & $7.9 \pm 1.0$ & - & - & - & - & - & - & - \\
\hline \multicolumn{14}{|l|}{ SSH04a-2 } \\
\hline NCA01 & 25 & 22 & 0.88 & $1.0 \%$ & $100 \%$ & $3.6 \pm 0.4$ & $0.0 \pm 0.0$ & $0.36 \pm 0.09$ & $0.41 \pm 0.08$ & $0.15 \pm 0.10^{\mathrm{NS}}$ & $0.35 \pm 0.07$ & $0.44 \pm 0.07$ & $0.19 \pm 0.09^{\mathrm{NS}}$ \\
\hline NCA05 & 42 & $33-38$ & $0.78-0.90$ & $7.3 \%$ & $88 \%$ & $2.9 \pm 0.4$ & $0.0 \pm 0.0$ & $0.37 \pm 0.10$ & $0.42 \pm 0.06$ & $0.15 \pm 0.16^{\mathrm{NS}}$ & $0.34 \pm 0.06$ & $0.43 \pm 0.08$ & $0.13 \pm 0.09^{\mathrm{NS}}$ \\
\hline NCA06 & 31 & $16-24$ & -0.77 & $3.1 \%$ & $100 \%$ & $3.6 \pm 0.5$ & $0.0 \pm 0.0$ & $0.34 \pm 0.06$ & $0.42 \pm 0.08$ & $0.14 \pm 0.09^{\mathrm{NS}}$ & $0.37 \pm 0.11$ & $0.47 \pm 0.06$ & $0.21 \pm 0.18^{\mathrm{NS}}$ \\
\hline Total & 119 & $85-104$ & $0.71-0.87$ & $5.3 \%$ & $100 \%$ & $4.3 \pm 0.4$ & - & - & - & - & - & - & - \\
\hline \multicolumn{14}{|l|}{ SSH04b } \\
\hline NCA13 & 10 & 10 & 1.00 & $2.5 \%$ & $100 \%$ & $3.0 \pm 0.3$ & $0.1 \pm 0.1$ & $0.56 \pm 0.06$ & $0.49 \pm 0.05$ & $-0.19 \pm 0.12^{\mathrm{NS}}$ & $0.56 \pm 0.06$ & $0.49 \pm 0.05$ & $-0.19 \pm 0.12^{\mathrm{NS}}$ \\
\hline NCA14 & 19 & $14-16$ & $0.72-0.83$ & $6.6 \%$ & $100 \%$ & $3.4 \pm 0.4$ & $0.0 \pm 0.0$ & $0.56 \pm 0.10$ & $0.49 \pm 0.06$ & $-0.15 \pm 0.17^{\mathrm{NS}}$ & $0.58 \pm 0.09$ & $0.52 \pm 0.06$ & $-0.15 \pm 0.16^{\mathrm{NS}}$ \\
\hline LOY03 & 23 & 22 & 0.95 & $9.8 \%$ & $100 \%$ & $2.8 \pm 0.4$ & $0.1 \pm 0.1$ & $0.63 \pm 0.08$ & $0.54 \pm 0.02$ & $-0.19 \pm 0.18^{\mathrm{NS}}$ & $0.64 \pm 0.08$ & $0.54 \pm 0.02$ & $-0.20 \pm 0.17^{\mathrm{NS}}$ \\
\hline LOY04 & 28 & $25-28$ & $0.89-1.00$ & $10.3 \%$ & $100 \%$ & $4.3 \pm 0.5$ & $0.4 \pm 0.2$ & $0.44 \pm 0.09$ & $0.48 \pm 0.05$ & $0.10 \pm 0.12^{\mathrm{NS}}$ & $0.46 \pm 0.08$ & $0.50 \pm 0.05$ & $0.11 \pm 0.12^{\mathrm{NS}}$ \\
\hline LOY05 & 12 & $9-11$ & $0.73-0.91$ & $12.5 \%$ & $88 \%$ & $2.5 \pm 0.3$ & $0.0 \pm 0.0$ & $0.38 \pm 0.09$ & $0.42 \pm 0.09$ & $0.04 \pm 0.14^{\mathrm{NS}}$ & $0.42 \pm 0.07$ & $0.49 \pm 0.10$ & $0.06 \pm 0.11^{\mathrm{NS}}$ \\
\hline LOY06 & 15 & 15 & 1.00 & $14.2 \%$ & $100 \%$ & $2.8 \pm 0.5$ & $0.0 \pm 0.0$ & $0.42 \pm 0.06$ & $0.44 \pm 0.06$ & $0.00 \pm 0.11^{\mathrm{NS}}$ & $0.42 \pm 0.06$ & $0.44 \pm 0.06$ & $0.00 \pm 0.11^{\mathrm{NS}}$ \\
\hline Total & 113 & $99-109$ & $0.88-0.96$ & $9.5 \%$ & $100 \%$ & $5.6 \pm 0.7$ & - & - & - & - & - & - & - \\
\hline Total PSH04 & 458 & $393-428$ & $0.86-0.93$ & $6.7 \%$ & $100 \%$ & $9.9 \pm 1.0$ & - & - & - & - & - & - & - \\
\hline
\end{tabular}


Cryptic species and genetic connectivity among populations of the coral Pocillopora damicornis (Scleractinia) in the tropical southwestern Pacific

- Marine Biology Original Paper-

Nicolas Oury, Pauline Gélin, Hélène Magalon

Corresponding author: Nicolas Oury, UMR ENTROPIE, Université de La Réunion, Faculté des Sciences et Technologies, 15 bd René Cassin, CS 92003 , 97744 St Denis Cedex 09, La Réunion. Email: nicolasoury@ hotmail.fr

Online Resource 13 Genetic differentiation among populations of Pocillopora PSH04 [ $F_{S T}$ (Weir and Cockerham 1984) in bottom left and $D_{\text {est }}$ (Jost 2008) in top right; truncated dataset in parentheses]. Only populations with at least 10 colonies were considered. (a) 11 loci and (b) 8 loci. Values in bold are significant $(P<0.001)$

(a) 11 loci

\begin{tabular}{|c|c|c|c|c|c|c|c|c|c|c|c|c|c|}
\hline & \multicolumn{3}{|c|}{ SSH04a-1 } & \multicolumn{3}{|c|}{ SSH04a-2 } & \multicolumn{6}{|c|}{ SSH04b } \\
\hline & & HE01 & CHE05 & NCA02 & NCA01 & NCA05 & NCA06 & NCA13 & NCA14 & LOY03 & LOY04 & LOY05 & LOY06 \\
\hline \multirow{3}{*}{ SSH04a-1 } & CHE01 $(11)$ & - & $\begin{array}{c}0.082 \\
(0.072)\end{array}$ & $\begin{array}{c}0.049 \\
(0.026)\end{array}$ & $\begin{array}{c}0.167 \\
(0.135)\end{array}$ & $\begin{array}{c}0.129 \\
(0.113) \\
\end{array}$ & $\begin{array}{c}0.164 \\
(0.141)\end{array}$ & $\begin{array}{c}0.257 \\
(0.260)\end{array}$ & $\begin{array}{c}0.249 \\
(0.249)\end{array}$ & $\begin{array}{c}0.178 \\
(0.167)\end{array}$ & \begin{tabular}{|c|}
0.182 \\
$(0.170)$ \\
\end{tabular} & $\begin{array}{c}0.243 \\
(0.259)\end{array}$ & $\begin{array}{c}0.189 \\
(0.200)\end{array}$ \\
\hline & CHE05 (21) & $\begin{array}{c}0.103 \\
(0.094)\end{array}$ & en-1 & $\begin{array}{c}0.070 \\
(0.071)\end{array}$ & & & $\begin{array}{c}0.168 \\
(0.166)\end{array}$ & $\begin{array}{c}0.156 \\
(0.151)\end{array}$ & & $\begin{array}{c}0.178 \\
(0.170)\end{array}$ & \begin{tabular}{|c|}
0.137 \\
$(\mathbf{0 . 1 2 5})$ \\
\end{tabular} & & \\
\hline & NCA02 $\left(\begin{array}{c}(10) \\
(9)\end{array}\right.$ & $\begin{array}{c}0.084 \\
(0.055) \\
\end{array}$ & $\begin{array}{c}\mathbf{0 . 1 4 4} \\
(\mathbf{0 . 1 4 4})\end{array}$ & - & $\begin{array}{c}0.135 \\
(\mathbf{0 . 1 2 9}) \\
\end{array}$ & $\begin{array}{c}\mathbf{0 . 1 2 5} \\
(\mathbf{0 . 1 0 4}) \\
\end{array}$ & $\begin{array}{c}0.153 \\
(\mathbf{0 . 1 2 6})\end{array}$ & $\begin{array}{c}0.258 \\
(0.243)\end{array}$ & $\begin{array}{c}0.225 \\
(0.237)\end{array}$ & $\begin{array}{c}0.208 \\
(0.198) \\
\end{array}$ & \begin{tabular}{|c|}
0.213 \\
$(0.191)$ \\
\end{tabular} & $\begin{array}{c}\mathbf{0 . 3 3 3} \\
(\mathbf{0 . 3 1 2}) \\
\end{array}$ & \\
\hline \multirow{3}{*}{ SSH04a-2 } & NCA01 $(25)$ & $\begin{array}{c}0.208 \\
(0.170)\end{array}$ & $\begin{array}{c}0.164 \\
(0.162)\end{array}$ & $\begin{array}{c}0.255 \\
(0.234)\end{array}$ & & \begin{tabular}{|c|}
$\mathbf{0 . 0 6 0}$ \\
$(\mathbf{0 . 0 5 3})$ \\
\end{tabular} & $\begin{array}{c}0.064 \\
(0.047)\end{array}$ & $\begin{array}{c}0.372 \\
(0.373)\end{array}$ & $\begin{array}{c}0.441 \\
(0.448)\end{array}$ & $\begin{array}{c}0.266 \\
(0.259)\end{array}$ & $\begin{array}{c}0.260 \\
(0.247)\end{array}$ & $\begin{array}{c}0.374 \\
(0.361)\end{array}$ & $\begin{array}{c}0.372 \\
(0.377)\end{array}$ \\
\hline & NCA05 $\left(\begin{array}{l}(42) \\
(39)\end{array}\right.$ & $\begin{array}{c}0.200 \\
(0.179)\end{array}$ & $\begin{array}{c}0.193 \\
(0.196)\end{array}$ & $\begin{array}{c}0.230 \\
(0.206)\end{array}$ & & $\begin{array}{l}- \\
-\end{array}$ & & & & $\begin{array}{c}0.173 \\
(0.169)\end{array}$ & & & \\
\hline & NCA06 $(24)$ & $\begin{array}{c}0.221 \\
(0.188)\end{array}$ & $\begin{array}{c}0.217 \\
(0.206)\end{array}$ & $\begin{array}{c}0.261 \\
(0.231)\end{array}$ & & $\begin{array}{c}0.055 \\
(0.046)\end{array}$ & 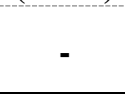 & $\begin{array}{c}0.303 \\
(0.304)\end{array}$ & & $\begin{array}{c}0.273 \\
(0.281)\end{array}$ & $\begin{array}{c}0.240 \\
(0.227)\end{array}$ & & \\
\hline \multirow{6}{*}{ SSH04b } & NCA13 (10) & $\begin{array}{c}0.258 \\
(0.252)\end{array}$ & $\begin{array}{c}0.233 \\
(0.232)\end{array}$ & $\begin{array}{c}0.310 \\
(0.307)\end{array}$ & $\begin{array}{c}0.371 \\
(0.358)\end{array}$ & $\begin{array}{c}0.337 \\
(\mathbf{0 . 3 3 5})\end{array}$ & $\begin{array}{c}0.360 \\
(0.347)\end{array}$ & & $\begin{array}{c}0.031 \\
(0.032)\end{array}$ & $\begin{array}{c}0.048 \\
(0.046)\end{array}$ & 33) & & \\
\hline & NCA14 $\begin{array}{l}(19) \\
(15)\end{array}$ & $\begin{array}{c}0.291 \\
(0.273)\end{array}$ & $\begin{array}{c}0.267 \\
(0.254)\end{array}$ & $\begin{array}{c}0.316 \\
(0.309)\end{array}$ & $\begin{array}{c}0.396 \\
(0.380)\end{array}$ & $\begin{array}{c}0.396 \\
(0.385)\end{array}$ & $\begin{array}{c}0.407 \\
(\mathbf{0 . 3 8 5})\end{array}$ & $\begin{array}{c}0.058 \\
(0.055)\end{array}$ & & $\begin{array}{c}\mathbf{0 . 0 9 9} \\
(0.097)\end{array}$ & $\begin{array}{l}95 \\
96) \\
96\end{array}$ & $\begin{array}{r}0.1 \\
(0.1\end{array}$ & \\
\hline & LOY03 $\begin{array}{l}(23) \\
(22)\end{array}$ & $\begin{array}{c}0.195 \\
(0.186)\end{array}$ & $\begin{array}{c}0.205 \\
(0.204)\end{array}$ & $\begin{array}{c}0.246 \\
(0.244)\end{array}$ & $\begin{array}{c}0.279 \\
(0.268)\end{array}$ & $\begin{array}{c}0.262 \\
(0.261)\end{array}$ & $\begin{array}{c}0.283 \\
(0.275)\end{array}$ & \begin{tabular}{|c|}
0.100 \\
$(0.099)$
\end{tabular} & $\begin{array}{c}0.148 \\
(0.142)\end{array}$ & 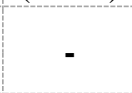 & $\begin{array}{c}0.060 \\
(0.054)\end{array}$ & $\begin{array}{c}0.138 \\
(0.111)\end{array}$ & $\begin{array}{c}0.048 \\
(\mathbf{0 . 0 3 4})\end{array}$ \\
\hline & LOY04 $(28)$ & $\begin{array}{c}0.248 \\
(0.215)\end{array}$ & $\begin{array}{c}0.229 \\
(0.207)\end{array}$ & $\begin{array}{c}0.310 \\
(0.277)\end{array}$ & $\begin{array}{c}0.338 \\
(0.303)\end{array}$ & \begin{tabular}{|c|}
0.301 \\
$(0.273)$
\end{tabular} & $\begin{array}{c}0.309 \\
(0.274)\end{array}$ & $\begin{array}{c}0.122 \\
(0.110)\end{array}$ & $\begin{array}{c}0.185 \\
(0.166)\end{array}$ & $\begin{array}{c}0.115 \\
(0.099)\end{array}$ & & & \begin{tabular}{|c|}
$\mathbf{0 . 0 2 8}$ \\
$\mathbf{0 . 0 2 7})$
\end{tabular} \\
\hline & LOY05 $(12)$ & $\begin{array}{c}0.277 \\
(0.257)\end{array}$ & $\begin{array}{c}0.272 \\
(0.256)\end{array}$ & $\begin{array}{c}0.388 \\
(0.365)\end{array}$ & $\begin{array}{c}0.389 \\
(0.368)\end{array}$ & \begin{tabular}{|c|}
0.367 \\
$(\mathbf{0 . 3 5 3})$
\end{tabular} & $\begin{array}{c}0.392 \\
(0.364)\end{array}$ & $\begin{array}{c}0.142 \\
(0.108)\end{array}$ & $\begin{array}{c}0.230 \\
(0.201)\end{array}$ & $\begin{array}{c}0.175 \\
(0.155)\end{array}$ & $\begin{array}{c}0.115 \\
(0.083)\end{array}$ & & \begin{tabular}{|c|}
0.064 \\
$(0.064)$
\end{tabular} \\
\hline & LOY06 (15) & $\begin{array}{c}0.269 \\
(0.266)\end{array}$ & $\begin{array}{c}0.263 \\
(0.261)\end{array}$ & $\begin{array}{c}0.321 \\
(0.317)\end{array}$ & $\begin{array}{c}0.391 \\
(0.379)\end{array}$ & $\begin{array}{c}\mathbf{0 . 3 6 1} \\
(\mathbf{0 . 3 5 8})\end{array}$ & $\begin{array}{c}0.390 \\
(0.379)\end{array}$ & $\begin{array}{c}0.025 \\
(0.028)\end{array}$ & $\begin{array}{c}0.099 \\
(0.100)\end{array}$ & $\begin{array}{c}0.093 \\
(0.078)\end{array}$ & $\begin{array}{c}0.106 \\
(0.093)\end{array}$ & $\begin{array}{c}0.168 \\
(0.146)\end{array}$ & \\
\hline
\end{tabular}


Online Resource 13 (Continued)

(b) 8 loci

\begin{tabular}{|c|c|c|c|c|c|c|c|c|c|c|c|c|c|}
\hline & & \multicolumn{3}{|c|}{ SSH04a-1 } & \multicolumn{3}{|c|}{ SSH04a-2 } & \multicolumn{6}{|c|}{ SSH04b } \\
\hline & & HE01 & CHE05 & NCA02 & NCA01 & NCA05 & NCA06 & NCA13 & NCA14 & LOY03 & LOY04 & LOY05 & LOY06 \\
\hline \multirow{3}{*}{ SSH04a-1 } & $\begin{array}{ll}\text { CHE01 } & (11) \\
(10)\end{array}$ & & $\begin{array}{c}0.086 \\
(0.072)\end{array}$ & $\begin{array}{c}\mathbf{0 . 0 6 9} \\
(0.036)\end{array}$ & $\begin{array}{c}0.131 \\
(0.083)\end{array}$ & $\begin{array}{c}0.082 \\
(0.053)\end{array}$ & $\begin{array}{c}0.125 \\
(0.084)\end{array}$ & $\begin{array}{c}0.243 \\
(0.255)\end{array}$ & $\begin{array}{c}0.222 \\
(0.212)\end{array}$ & \begin{tabular}{|c|}
0.115 \\
$(0.106)$
\end{tabular} & $\begin{array}{c}0.123 \\
(0.120)\end{array}$ & \begin{tabular}{|c|}
0.162 \\
$(0.183)$ \\
\end{tabular} & $\begin{array}{c}0.147 \\
(0.154)\end{array}$ \\
\hline & CHE05 $(21)$ & \begin{tabular}{c|c}
0.117 \\
$(0.097)$
\end{tabular} & - & $\begin{array}{c}\mathbf{0 . 1 0 8} \\
(\mathbf{0 . 0 9 5})\end{array}$ & $\begin{array}{c}0.100 \\
(0.092)\end{array}$ & $\begin{array}{c}\mathbf{0 . 0 7 8} \\
(\mathbf{0 . 0 5 6})\end{array}$ & $\begin{array}{c}\mathbf{0 . 1 3 2} \\
(\mathbf{0 . 1 0 4})\end{array}$ & $\begin{array}{c}\mathbf{0 . 1 7 6} \\
(\mathbf{0 . 1 6 7 )}\end{array}$ & $\begin{array}{c}0.262 \\
(0.210)\end{array}$ & $\begin{array}{c}0.141 \\
(0.129)\end{array}$ & $\begin{array}{c}0.097 \\
(0.090)\end{array}$ & $\begin{array}{c}0.194 \\
(0.172)\end{array}$ & $\begin{array}{c}\mathbf{0 . 1 8 8} \\
(\mathbf{0 . 1 7 5})\end{array}$ \\
\hline & $\begin{array}{cc}\mathrm{NCA02} & (10) \\
(9)\end{array}$ & $\begin{array}{c}\mathbf{0 . 1 1 5} \\
(0.078)\end{array}$ & $\begin{array}{c}0.192 \\
(0.171)\end{array}$ & - & $\begin{array}{c}0.093 \\
(0.077)\end{array}$ & & & $\begin{array}{c}\mathbf{0 . 3 2 1} \\
(\mathbf{0 . 3 0 5})\end{array}$ & & & & & \\
\hline \multirow{3}{*}{ SSH04a-2 } & $\begin{array}{ll}\text { NCA01 } & (25) \\
(20)\end{array}$ & $\begin{array}{c}0.202 \\
(0.146)\end{array}$ & $\begin{array}{c}0.153 \\
(\mathbf{0 . 1 3 4})\end{array}$ & $\begin{array}{c}0.281 \\
(0.250)\end{array}$ & - & $\begin{array}{c}\mathbf{0 . 0 4 7} \\
(0.024)\end{array}$ & \begin{tabular}{|c|}
$\mathbf{0 . 0 4 6}$ \\
$(0.024)$ \\
\end{tabular} & $\begin{array}{c}0.432 \\
(0.408)\end{array}$ & \begin{tabular}{|c|}
0.473 \\
$(0.446)$ \\
\end{tabular} & $\begin{array}{c}0.265 \\
(0.249)\end{array}$ & & \begin{tabular}{|c|c}
0.294 \\
$(0.287)$ \\
\end{tabular} & \\
\hline & $\begin{array}{ll}\text { NCA05 } & (42) \\
(31)\end{array}$ & $\begin{array}{c}0.172 \\
(0.124)\end{array}$ & $\begin{array}{c}0.176 \\
(0.152)\end{array}$ & $\begin{array}{c}0.227 \\
(0.180)\end{array}$ & $\begin{array}{c}0.105 \\
(0.063)\end{array}$ & & $\begin{array}{c}\mathbf{0 . 0 2 6} \\
(0.004)\end{array}$ & $\begin{array}{c}0.361 \\
(0.332)\end{array}$ & \begin{tabular}{|c|}
0.474 \\
$(0.418)$
\end{tabular} & & & \begin{tabular}{c|c|}
0.250 & \\
$(0.228)$ &
\end{tabular} & $\begin{array}{c}0.347 \\
(0.324)\end{array}$ \\
\hline & $\begin{array}{ll}\text { NCA06 } & (31) \\
(14)\end{array}$ & \begin{tabular}{c|c|}
0.241 \\
$(0.141)$
\end{tabular} & $\begin{array}{c}0.242 \\
(0.177) \\
\end{array}$ & $\begin{array}{c}0.315 \\
(0.223) \\
\end{array}$ & $\begin{array}{c}0.127 \\
(0.091) \\
\end{array}$ & $\begin{array}{r}\mathbf{0 . 0 6 5} \\
(0.024) \\
\end{array}$ & 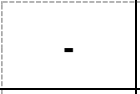 & $\begin{array}{c}0.449 \\
(0.400) \\
\end{array}$ & \begin{tabular}{|c|}
0.523 \\
$(\mathbf{0 . 4 5 5})$ \\
\end{tabular} & & & & \\
\hline \multirow{6}{*}{ SSH04b } & NCA13 (10) & \begin{tabular}{c|c|}
0.271 \\
$(0.273)$
\end{tabular} & $\begin{array}{c}0.262 \\
(0.255)\end{array}$ & $\begin{array}{l}0.370 \\
(0.37)\end{array}$ & $\begin{array}{c}0.424 \\
(0.398)\end{array}$ & $\begin{array}{c}0.402 \\
(0.390)\end{array}$ & $\begin{array}{c}\mathbf{0 . 4 5 3} \\
(\mathbf{0 . 3 9 5})\end{array}$ & & $\begin{array}{c}\mathbf{0 . 0 3 9} \\
(0.028) \\
\end{array}$ & $\begin{array}{c}0.029 \\
(0.026)\end{array}$ & $\begin{array}{c}0.048 \\
(0.047)\end{array}$ & \begin{tabular}{c|}
0.047 \\
$(0.013)$ \\
\end{tabular} & \\
\hline & $\begin{array}{ll}\text { NCA14 } & (19) \\
(13)\end{array}$ & $\begin{array}{c}0.275 \\
(0.250)\end{array}$ & $\begin{array}{c}0.287 \\
(0.253)\end{array}$ & $\begin{array}{c}\mathbf{0 . 3 4 9} \\
(\mathbf{0 . 3 3 2})\end{array}$ & $\begin{array}{r}\mathbf{0 . 4 2 6} \\
(\mathbf{0 . 3 8 7})\end{array}$ & $\begin{array}{c}\mathbf{0 . 4 2 0} \\
(\mathbf{0 . 3 8 4})\end{array}$ & $\begin{array}{c}0.461 \\
(0.381)\end{array}$ & $\begin{array}{r}0.07 \\
(0.05\end{array}$ & & $\begin{array}{c}\mathbf{0 . 0 7 7} \\
(\mathbf{0 . 0 6 3})\end{array}$ & & \begin{tabular}{c|c}
0.181 \\
$(0.140)$
\end{tabular} & $\begin{array}{c}0.025 \\
(\mathbf{0 . 0 3 6})\end{array}$ \\
\hline & LOY03 $\begin{array}{l}(23) \\
(22)\end{array}$ & $\begin{array}{c}0.188 \\
(0.187)\end{array}$ & $\begin{array}{c}0.217 \\
(0.209)\end{array}$ & $\begin{array}{c}0.276 \\
(0.275)\end{array}$ & $\begin{array}{c}\mathbf{0 . 3 2 9} \\
(\mathbf{0 . 3 0 7})\end{array}$ & $\begin{array}{c}\mathbf{0 . 3 1 3} \\
(\mathbf{0 . 3 0 2})\end{array}$ & $\begin{array}{c}0.351 \\
(0.305)\end{array}$ & $\begin{array}{c}0.110 \\
(0.108)\end{array}$ & $\begin{array}{c}0.137 \\
(\mathbf{0 . 1 2 5})\end{array}$ & & & & \\
\hline & LOY04 & \begin{tabular}{c|c|}
0.189 & \\
$(0.176)$ &
\end{tabular} & $\begin{array}{c}0.194 \\
(0.178)\end{array}$ & $\begin{array}{c}0.287 \\
(0.274)\end{array}$ & $\begin{array}{c}0.327 \\
(0.292)\end{array}$ & $\begin{array}{c}0.300 \\
(0.279)\end{array}$ & $\begin{array}{c}0.319 \\
(0.260)\end{array}$ & $\begin{array}{c}0.090 \\
(0.082)\end{array}$ & $\begin{array}{c}0.133 \\
(0.109) \\
\end{array}$ & $\begin{array}{c}0.109 \\
(0.098)\end{array}$ & & \begin{tabular}{c|c|}
0.068 & \\
$(0.043)$ &
\end{tabular} & $\begin{array}{c}\mathbf{0 . 0 3 5} \\
(0.033)\end{array}$ \\
\hline & $\operatorname{LOY05}_{(\mathbf{8})}^{(12)}$ & \begin{tabular}{r|r|r|}
0.234 & \\
$(0.212)$ &
\end{tabular} & $\begin{array}{c}0.275 \\
(0.237)\end{array}$ & $\begin{array}{c}0.406 \\
(0.376)\end{array}$ & $\begin{array}{c}0.397 \\
(0.357)\end{array}$ & $\begin{array}{c}0.379 \\
(0.352)\end{array}$ & $\begin{array}{c}0.429 \\
(0.351)\end{array}$ & $\begin{array}{c}\mathbf{0 . 1 4 7} \\
(0.069)\end{array}$ & $\begin{array}{c}0.241 \\
(0.156)\end{array}$ & $\begin{array}{c}0.184 \\
(0.155)\end{array}$ & $\begin{array}{c}\mathbf{0 . 1 1 8} \\
(0.060)\end{array}$ & & $\begin{array}{c}\mathbf{0 . 0 5 1} \\
(0.035)\end{array}$ \\
\hline & LOY06 (15) & \begin{tabular}{c|c|}
0.250 \\
$(0.255)$ \\
\end{tabular} & $\begin{array}{c}0.261 \\
(0.252) \\
\end{array}$ & $\begin{array}{c}0.334 \\
(0.337) \\
\end{array}$ & $\begin{array}{c}0.434 \\
(0.411) \\
\end{array}$ & $\begin{array}{c}0.406 \\
(0.394) \\
\end{array}$ & $\begin{array}{c}0.458 \\
(0.401) \\
\end{array}$ & $\begin{array}{c}0.013 \\
(0.013) \\
\end{array}$ & \begin{tabular}{|c|}
0.063 \\
$(0.061)$ \\
\end{tabular} & $\begin{array}{c}0.083 \\
(\mathbf{0 . 0 8 0}) \\
\end{array}$ & $\begin{array}{c}0.072 \\
(0.066) \\
\end{array}$ & $\begin{array}{r}\mathbf{0 . 1 7 9} \\
(0.109) \\
\end{array}$ & \\
\hline
\end{tabular}


Cryptic species and genetic connectivity among populations of the coral Pocillopora damicornis (Scleractinia) in the tropical southwestern Pacific - Marine Biology Original Paper-

Nicolas Oury, Pauline Gélin, Hélène Magalon

Corresponding author: Nicolas Oury, UMR ENTROPIE, Université de La Réunion, Faculté des Sciences et Technologies, 15 bd René Cassin, CS 92003, 97744 St Denis Cedex 09, La Réunion. Email: nicolasoury@ hotmail.fr

Online Resource 14 Relative migration networks for (a) all Pocillopora PSH04 colonies and (b) each cluster separately (Entire_11 dataset). Nodes represent populations and arrows represent migrations

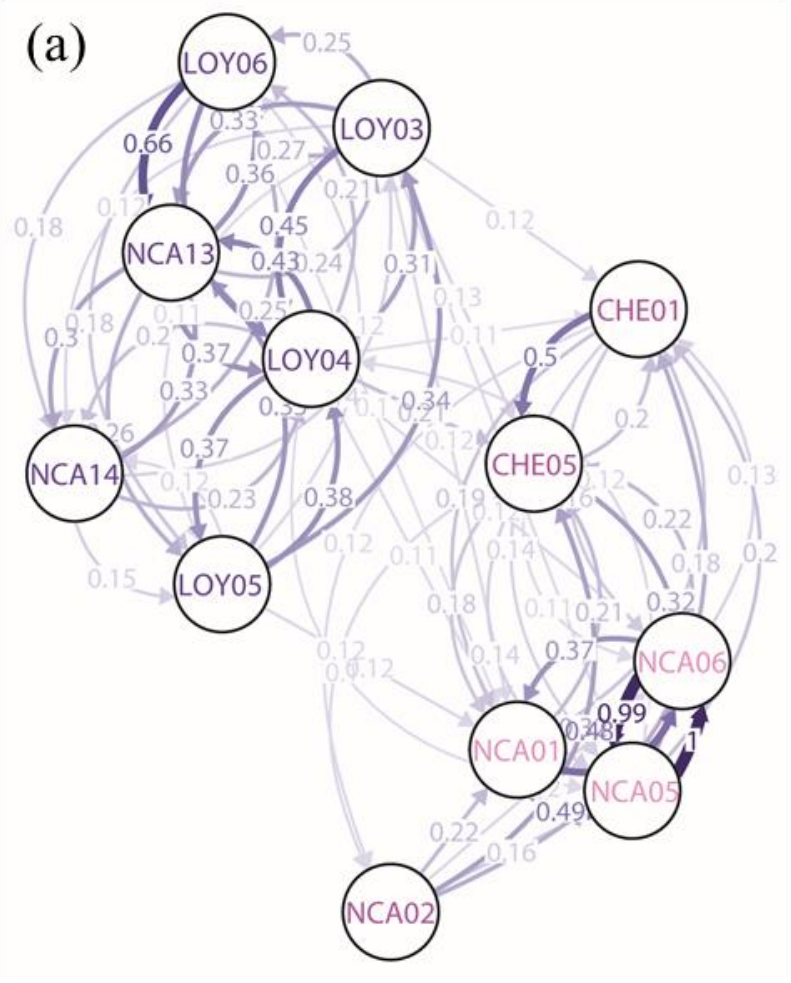

(b)

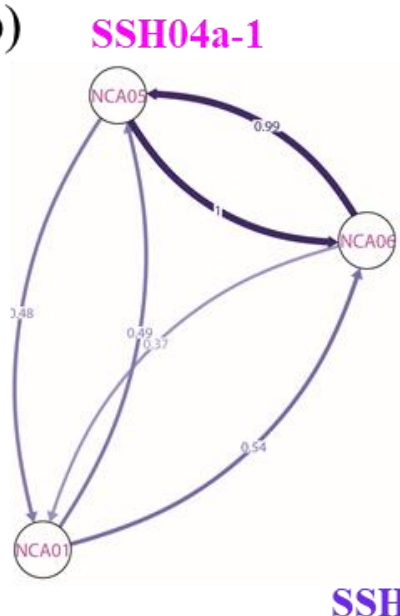

SSH04a-2

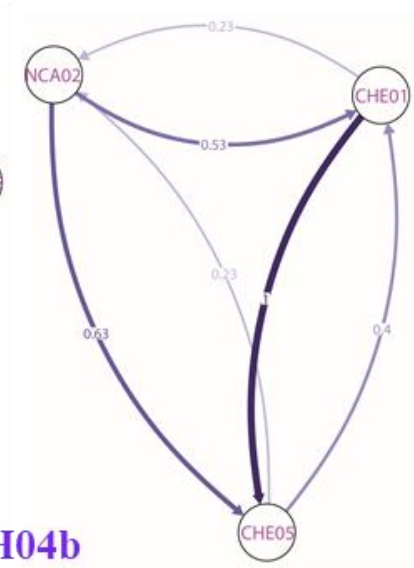

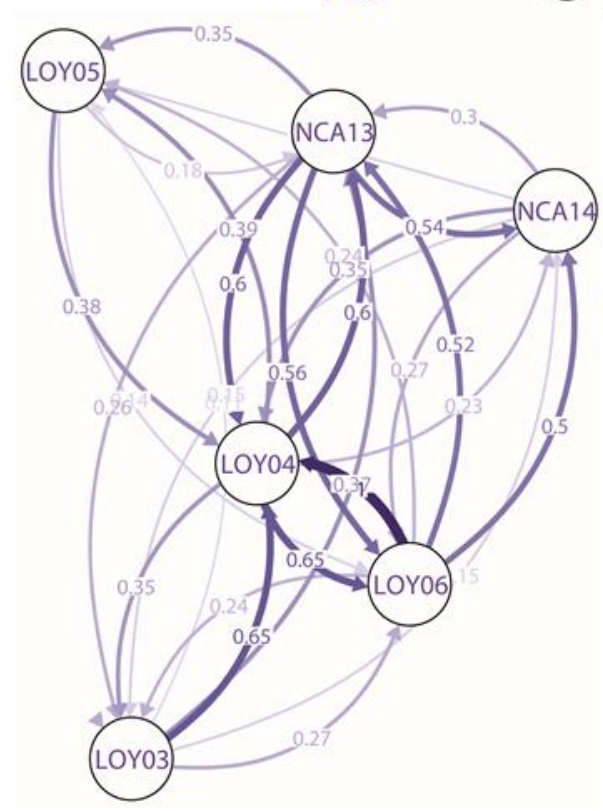


Cryptic species and genetic connectivity among populations of the coral Pocillopora damicornis (Scleractinia) in the tropical southwestern Pacific - Marine Biology Original Paper-

Nicolas Oury, Pauline Gélin, Hélène Magalon

Corresponding author: Nicolas Oury, UMR ENTROPIE, Université de La Réunion, Faculté des Sciences et Technologies, 15 bd René Cassin, CS 92003, 97744 St Denis Cedex 09, La Réunion. Email: nicolasoury @ hotmail.fr

Online Resource 15 Pocillopora PSH04. Miscellany pictures for each Secondary Species Hypothesis (SSH) and each cluster, representing corallum macromorphology diversity (scale $\approx 5 \mathrm{~cm}$ )

SSH04a-1
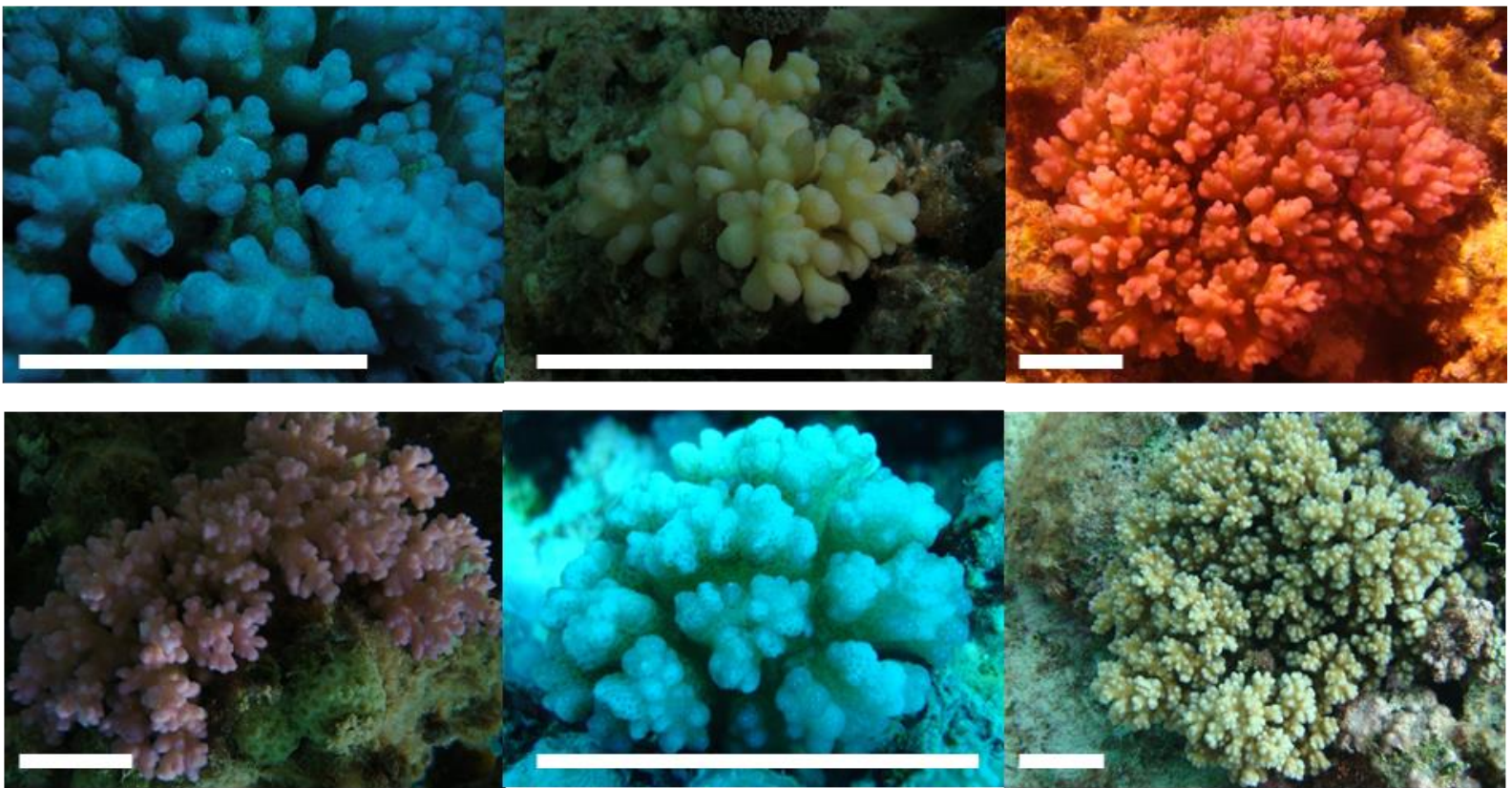

\section{SSH04a-2}
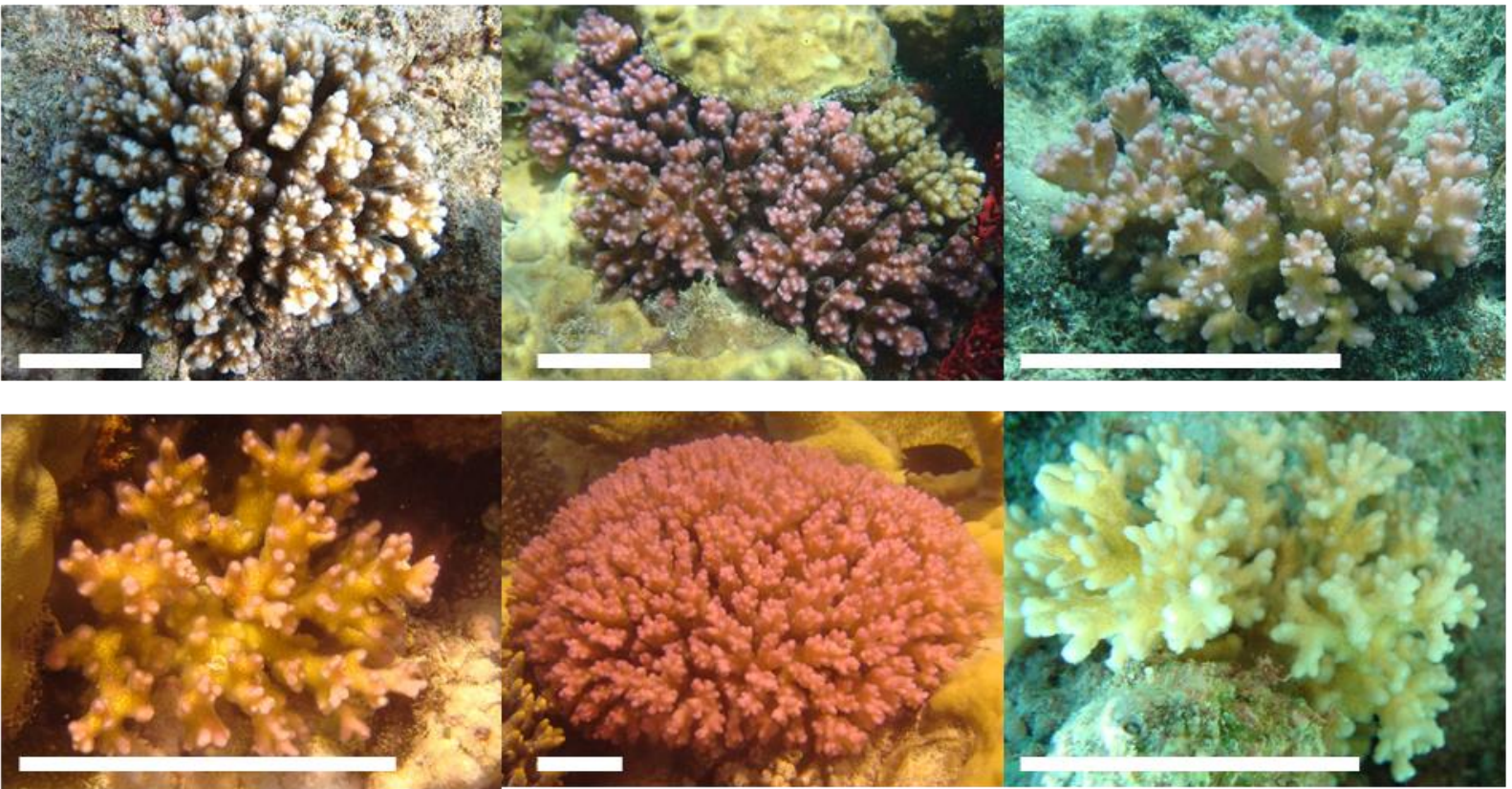

\section{SSH04b}
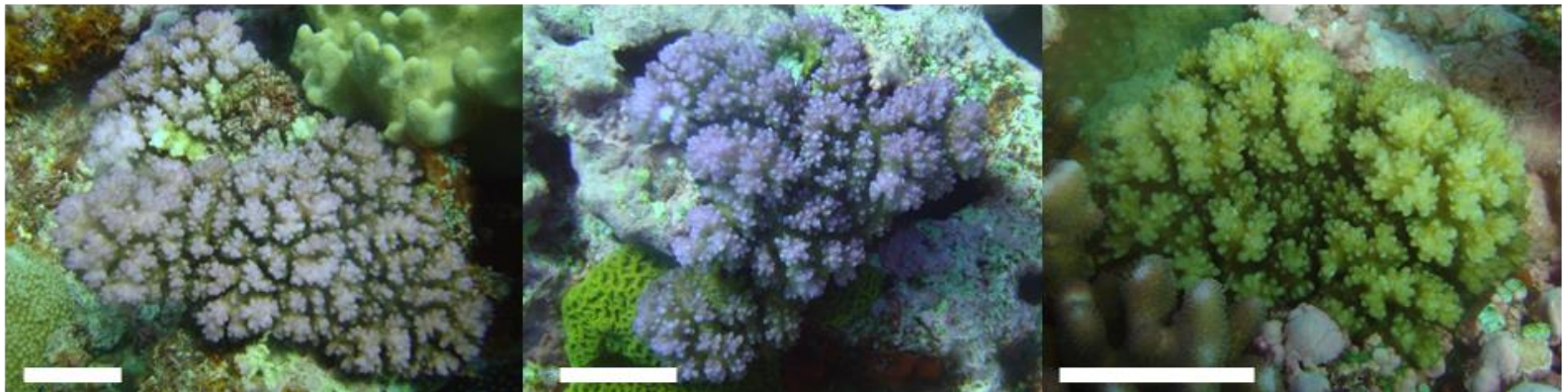